\title{
The role of strategic alliances in VC exits: evidence from the biotechnology industry
}

\section{Leonhard Brinster , Christian Hopp \& Tereza Tykvová}

To cite this article: Leonhard Brinster, Christian Hopp \& Tereza Tykvová (2020) The role of strategic alliances in VC exits: evidence from the biotechnology industry, Venture Capital, 22:3, 281-313, DOI: $10.1080 / 13691066.2020 .1814192$

To link to this article: https://doi.org/10.1080/13691066.2020.1814192

\section{Published online: 07 Sep 2020.}

Submit your article to this journal

Џ Article views: 94

Q View related articles $\asymp$

View Crossmark data \lceil

4

Citing articles: 1 View citing articles $๘$ 


\title{
The role of strategic alliances in VC exits: evidence from the biotechnology industry
}

\author{
Leonhard Brinster ${ }^{\mathrm{a}}$, Christian Hopp ${ }^{\mathrm{b}, \mathrm{c}}$ and Tereza Tykvovád
}

aChair of Corporate Finance, University of Hohenheim, Stuttgart, Germany; ${ }^{b}$ Chair of Technology Entrepreneurship, RWTH Aachen University, Aachen, Germany; 'Business School, Bern University of Applied Sciences, Bern, Switzerland; ${ }^{d}$ Chair of Private Markets and Alternative Investments, University of St. Gallen, St. Gallen, Switzerland

\begin{abstract}
In this study, we analyze the impact of strategic alliances on VC exits. We explicitly ask whether strategic alliances may serve as a certifying device for new potential investors and whether the role alliances play differs in IPO and M\&As. We hypothesize that strategic alliances serve as a certifying device particularly in instances with many uninformed buyers (IPOs) but not when there is a single buyer (M\&As). To empirically test this hypothesis, we draw on a sample of 663 US VC-backed biotechnology companies founded between 2004 and 2008. We explicitly control for observed and unobserved heterogeneity in our cohort sample, alleviate concerns relating to self-selection into alliance activity, and assuage methodological concerns with respect to censoring. Our findings suggest that alliances improve the probability of successful exits for IPOs, but not for M\&As. Moreover, we find a smaller effect than prior studies do.
\end{abstract}

\section{ARTICLE HISTORY}

Received 10 August 2019

Accepted 20 August 2020

\section{KEYWORDS}

Strategic alliance; venture capital; biotechnology; IPO; M\&A

\section{Introduction}

Strategic alliances play an important role in the financing and growth of companies. Strategic alliances are especially important for companies that lack resources. Alliances can provide them with access to absent technology, equipment, or know-how. Not surprisingly, the role of alliances is also gaining momentum and importance for companies that have raised venture capital (VC) and that are by definition in the very early stages of organizational development (Lindsey 2008; Wang et al. 2012; Ozmel, Robinson, and Stuart 2013). Because early-stage ventures usually require substantial amounts of capital, strategic alliances present an important source of funding but may at the same time also open avenues for leveraging complementary assets in accessing a new customer base.

While strategic alliances are ubiquitous for young and innovative companies, their role in determining the growth trajectory of VC-financed ventures and importantly their role for the exit channel for the participating VC firms are under-researched. We therefore specifically investigate how strategic alliances affect exit outcomes of the venture financing process. 
We consider the context when VC firms themselves are about to exit the investment, either through an initial public offering (IPO) or a merger/acquisition (M\&A). Evidently, the decision to exit an investment might raise eyebrows among potential buyers about the underlying quality of the transaction they are about to enter (Cumming 2008; Alexander and Cumming 2020). Not surprisingly, the absence of sufficient collateral and the high asset-specific knowledge exacerbates the bilateral dependency of VC firms and potential buyers. Certification through a third party is one way to mitigate the information asymmetry between contracting parties. In this study, we therefore ask whether strategic alliances may serve as a certifying device and whether their role differs based on the type of exit (IPO vs. M\&A).

Prior work has argued that strategic alliances can reduce information asymmetries between the company and potential buyers, and thus positively affect the chances for a successful exit (see, e.g., Lindsey 2008; Wang et al. 2012; Ozmel, Robinson, and Stuart 2013). While prior studies do not deal with differences between different types of exits, we argue that the alliance effect may vary with the type of exit.

Following Cumming and Johan (2008) we build on the notion that IPOs will be the most difficult exit choice for VC firms because they need to mitigate the highest risk of asymmetric information. When companies go public, many potential uninformed buyers exist. Each of them faces the free riding problem, which reduces their incentive to collect information (Hochberg, Ljungqvist, and Lu 2007; Hochberg 2012). In this situation, a potentially uninformed buyer may benefit from a certification of company quality through a third party. In out setting, this third party is the strategic partner that certifies the quality of a particular company through its willingness to form a strategic alliance with this company. The situation regarding M\&A acquisitions is different. Here, the single acquiring party will have much stronger incentives to conduct deep due diligence. Consequently, we argue that IPO and M\&A exits have different needs for certification (see, e.g., Cumming and Johan 2008; Giot and Schwienbacher 2007). Therefore, we expect that alliances are an important certification device before IPOs, and that they are less important before M\&As.

We study the role of strategic alliances for entrepreneurial companies in the biotech sector. We believe that VC-backed biotechnology companies are the ideal setting to investigate whether strategic alliances are associated with certification for potential buyers at the exit because VC-backed biotechnology companies face a long product development cycle with substantial risks and uncertainties. At the same time, VC firms want to realize fast exits because they are under pressure to return funds to their investors. Exiting is difficult when companies are in early stages of their product development cycle. Under these circumstance, strategic alliances can serve as a certification device since others can observe alliance formation. Prior research documents positive abnormal returns around the announcement of these events (Stuart 1998; Anand and Khanna 2000).

Our research questions thus are whether strategic alliances impact on M\&A and IPO exits and whether this effect is stronger for IPOs. To answer these questions, we employ a cohort study of 663 US-based biotech ventures founded between 2004 and 2008. Hence, these ventures were set up under similar regulatory and economic environments. The random sampling based on the foundation year alleviates the concerns of left censoring, in which companies are prone to heterogeneity in terms of the development 
stage. We use a host of control variables to control for other observable characteristics that affect both the chances to form a strategic alliance and to exit successfully and subsequently employ lagged variables to deal with potential reverse causation. Lastly, we apply different approaches that account for unobserved heterogeneity to infer the causal effect of strategic alliances on the chances of exit. We start by employing company and time fixed effects. The former ensures that we eliminate time-invariant characteristics at the company level, while the latter allows us to account for changes in economic conditions. We then complement these findings with results from a propensity score matching approach that controls for potential endogeneity in the choice for or against a strategic alliance.

In contrast to prior work on strategic alliances and M\&As (e.g., Ozmel, Robinson, and Stuart 2013) we do not find evidence that strategic partners, as insiders, may themselves take over the VC-financed companies, which would corroborate a positive association between strategic alliances and M\&As. In our sample of 663 companies, we track the buyers' identity and find only four cases in which the strategic alliance partner took over the VC-financed company. The often assumed most obvious way in which strategic alliances and M\&As is therefore more anecdotal: "[...] the transformation from strategic technology alliances to merger and acquisitions hardly ever takes place" (Hagedoorn and Sadowski 1999). In turn, we report that strategic alliances are less important for the success of an M\&A exit compared to an IPO exit. We therefore set forth that VC exits have different needs for certification. More specifically, we confirm a positive effect of strategic alliances only for IPOs, but not for M\&As. Further, we also report that the magnitude of the alliance effect is less than that reported in prior studies and we challenge the pervasive assumption of temporally constant effects. While the overall effect of strategic alliances on M\&As is insignificant, it is negative in the short term and turns positive in the long term.

The rest of the paper is organized as follows: We present the theoretical background in section 2. Section 3 describes our dataset and variables. Afterwards, we discuss the methodology in section 4 . Section 5 presents the results. Finally, in section 6 , we discuss the main findings, possible implications, and limitations of this study.

\section{Theoretical background}

When taking a company public, incumbent investors generally have an informational advantage over potential buyers (Welch 1989; Allen and Faulhaber 1989), who have to rely on the information that incumbents provide. While incumbent investors may engage in road shows and provide gloomy outlooks, talk is literally cheap. The incumbents' selfinterests and information asymmetries can work to the detriment of potential buyers that are expected to inject new cash into the business in exchange for the incumbents' valuecreation promise.

The problem of uncertainty regarding company quality is pronounced for young biotechnology companies. A typical biotechnology company faces a long product development cycle, usually 7 to 10 years, as the company advances from the first idea through clinical trials and the FDA approval process (Deeds, Decarolis, and Coombs 1997). During this time, the outcome is uncertain, the company needs cash, and does not generate any revenue. Given the intangible nature of knowledge and the absence of collateral, 
substantial uncertainty persists. It is therefore difficult for potential buyers to judge whether such a company will succeed in advancing products through the long development cycle to generate revenues.

For potential buyers in an IPO, the availability of information is one of the key determinants of subsequent resource allocation. Therefore, positive information from a credible third party will play a crucial role in reducing information asymmetries and mitigating potential agency conflicts (Bushman, Piotroski, and Smith 2004). Without such information, new buyers may fear that they will invest in low-quality companies.

As such, the literature discusses several certification devices that companies can provide to reduce information asymmetry in the course of an IPO. The presence of a reputable VC may ensure that a young company is not holding back IPO-relevant information (Megginson and Weiss 1991), though the incentives of the selling VC firms create grounds for adverse selection (Lee and Wahal 2004). Daily et al. (2003) review possible variables related to IPO quality, such as company size, auditor reputation, and VC backing. Basdeo et al. (2006) argue that market participants observe the strategic actions of focal companies and form expectations of abilities and reputations. One of the strongest quality indicators that IPO participants may receive is the ability of another company to attest to the quality of the underlying company in which they are about to invest. Stuart, Hoang, and Hybels (1999) and Chen, Hambrick, and Pollock (2008) argue that companies affiliate with a prominent partner to signal their company value. Hoenig and Henkel (2015) suggest that strategic alliances are more reflective of the companies' underlying technological advantage than are patent grants.

We therefore expect that a VC-financed company's behavior in the form of a strategic alliance reveals unobservable technological attributes. Strategic alliances convey positive information that reflect the strategic goals, intentions, and abilities of VC-financed companies to outsiders (Milgrom and Roberts 1986; Basdeo et al. 2006). Hence, a strategic alliance attests to the underlying quality of the company and improves its chances to go public.

In IPOs, individual investors face the free riding problem. Because information is costly to obtain, a single investor does not have incentives to collect information and the market could break down. For the market to operate, the certification of the IPO quality through a third party would be beneficial. A strategic alliance with a third party may provide such a certification. An uninformed investor may interpret it as a certification of quality if another company is willing to form a strategic alliance with a particular company. The situation in M\&A exits is different. Before an acquisition, there are only a few potential buyers (or in some cases, only a single buyer). M\&A transactions are subject to severe scrutiny by potential buyers and involve due diligence procedures and multi-round negotiations. Consequently, we argue that IPO and M\&A exits have different needs for certification. Instead of relying on outside certification, acquirers screen the target themselves. Hence, while being important for IPO exits, strategic alliances may be irrelevant as a quality indicator in M\&A exits. Jääskeläinen and Maula (2014) argue that direct ties (certification effect) are more relevant in IPOs whereas indirect ties are more relevant in acquisitions as they help in the matching between the focal firm with the potential acquirers. 
In addition, Cumming (2008) argues that if VC firms have weaker control rights, the likelihood of an IPO is higher than that of an M\&A. Strategic alliances might lead to more involved interests, and hence, to weaker VC control rights. This would mean that for companies with strategic alliances, VC firms tend to exit via an IPO rather than via an M\&A.

Finally, in the short term, the exit motives might be at odds with the intentions of existing strategic alliance partners. This may create conflicts between the project-level decision (and cash flow) rights of existing alliance partners and potential acquirers (Robinson and Stuart 2007b), leading to a preference for an IPO over an M\&A. We therefore argue that if a VC-financed company entered a strategic alliance, the likelihood of that company being acquired through an M\&A transaction is lower than the likelihood of going public.

\section{Data}

\subsection{Sample}

Our sample consists of 663 US VC-backed biotechnology companies founded between 2004 and 2008. We draw this sample of companies from Dow Jones VentureSource and from the Thomson One database. We employ all available records for VC-backed companies in the biotechnology sector from the combination of these two databases. We exclude companies that did not disclose the VC investors and eliminate duplicate entries.

Our aim is to create a homogeneous sample (in terms of company age and industry) that we subsequently track over time. This type of cohort study reduces concerns about unobserved heterogeneity due to the firms being at different development stages. With this design, we also remove concerns about left censoring. Because we observe all companies from their birth, there are no relevant events before the study enrollment.

For these companies, we track their strategic alliance activity, VC financing, patenting, and exits until 2014. We extract information about strategic alliances from S\&P Capital IQ, which defines a strategic alliance as a "relationship between two or more companies to pursue a common objective through mutual cooperation, pooling of resources, etc.".' Data on VC financing and exits come from Dow Jones VentureSource and from the Thomson One database. We employ data on patents from Patstat. We use the online access to Patstat of the European Patent Office (EPO) and collect information about patents by both the application and publication dates.

\subsection{Dependent variables: IPO exit and M\&A exit}

We are interested in understanding the role of strategic alliances in VC exits. Following much of the literature (e.g., Hochberg, Ljungqvist, and Lu 2007; Sørensen 2007; Das, Jo, and Kim 2011; Dai, Jo, and Kassicieh 2012; Nahata, Hazarika, and Tandon 2014), we assume that VC firms aim to exit their companies either via an IPO or an M\&A. Table 1 shows that 78 companies were taken public and 99 companies were exited via an M\&A. If a company was not exited by 2014 , we treat it as unsuccessful. This approach is common in studies that rely on commercial databases that are likely to underreport bankruptcies (generally, participants have a higher reluctance to report this instance appropriately). 


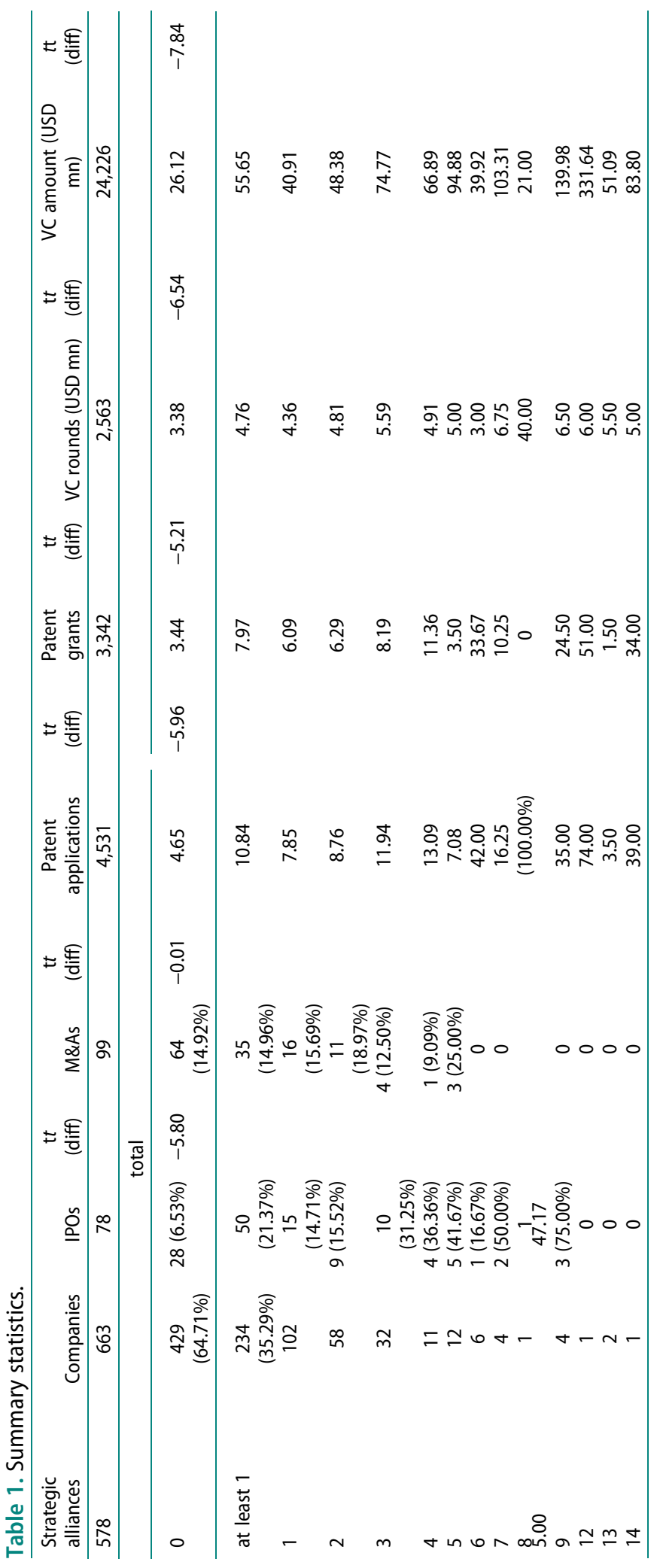


We define two dependent variables. If a company went public in a particular year, then the dummy variable IPO exit equals one in that year and in all succeeding years (and zero otherwise). The second dependent variable $M \& A$ exit equals one if the company exited through $M \& A$ and is equal to one in all succeeding years (and zero otherwise).

The problems with truncation and censoring have been well documented in the literature on strategic alliances and VC exits (Yang and Aldrich 2012; Ozmel, Robinson, and Stuart 2013). The problem of right censoring is that a sample could end before we can observe a future exit event. To ensure that we did not introduce an artificial bias into our analysis, we follow previously published work in this area. For example, Nahata (2008) uses an investment sample ending in 2001 and classifies all companies that did not exit successfully by the beginning of 2006 as unsuccessful exits. Hochberg, Ljungqvist, and Lu (2007) assume that a company for which they found no information about an exit at the fund's tenth anniversary was liquidated. Our success rate is comparable to those reported in prior studies. In total, $26.7 \%$ of companies from our sample had successful exits. This percentage is within the range reported in recent studies; for example, Nahata, Hazarika, and Tandon (2014) report 24.2\% and Ozmel, Robinson, and Stuart (2013) state 30.6\%. Nevertheless, we provide additional analyses in the robustness section to ensure that we do not underreport successful exits.

\subsection{Independent variables}

Our main independent variables are related to the companies' involvement in strategic alliances. In our regressions, we also include other variables that may be used as certification devices (such as patents) at the exit as well as further controls.

Our sample companies were involved in 578 strategic alliances (see Table 1). The average number of strategic alliances per company is 0.87 for the whole sample and 2.5 alliances among companies with at least one alliance. As Table 1 shows, the distribution of the number of strategic alliances is heavily right-skewed; $64.7 \%$ of companies have no alliances. The median number of strategic alliances of the companies that have at least one alliance is two. Table 1 also demonstrates that companies that enter at least one strategic alliance have a higher likelihood of an IPO than companies without strategic alliances ( $21.4 \%$ vs. $6.5 \%$ ), while the likelihood of an M\&A is almost the same (close to $15 \%)$. In the next sections, we elaborate on these first insights with multivariate analyses.

We include two types of strategic alliance measures in our analyses. First, we generate a variable that counts the number of strategic alliances. Second, we create a dummy variable that indicates whether a company had any strategic alliances. In addition, we include variations of these two variables for the time periods in which the companies formed their strategic alliances.

Our sample companies applied for 4,531 patents and were granted 3,342 patents. Companies that do not have any strategic alliance were granted 3.44 patents on average and companies with at least one alliance were granted 7.97 patents on average (see Table 1).

In our regressions, we also control for VC investment characteristics. Along with the total number of involved VC firms, we include a variable that counts the number of new VC firms. A higher number of VC firms may have a positive effect, as more VC firms may add higher value. However, syndication, especially for VC firms that joined recently, might lead 
to conflicts of interest. We also include the amount of VC investments and the number of VC rounds. Table 1 shows that between 2004 and 2014, our sample companies obtained USD 24.2 bn in 2,563 VC financing rounds. Companies with at least one strategic alliance obtain more VC rounds and higher VC amounts than companies that enter no alliances.

We also control for the size of the VC network since ties between VC firms might affect the exit choice and the likelihood of entering a strategic alliance. We define the network as the ratio of the number of syndication partners to the total number of active VC firms in a particular time period. A VC firm is active if it invested in at least one portfolio company in this period. To construct this measure at the company level, we use the average network of all involved VC firms.

\section{Methods}

\subsection{Pooled OLS and fixed effect estimations}

We construct a panel dataset on an annual basis and first estimate the relationship between strategic alliances and the different types of exits with pooled OLS regressions. We begin by estimating different specifications of the dependent variable IPO exit. We exclude all companies that exited through an M\&A. We proceed similarly for the dependent variable $M \& A$ exit. $^{2}$

A problem with pooled OLS models is that they do not account for unobserved heterogeneity across companies that may be related to the likelihood of an IPO or an M\&A. For example, high-quality companies may have a higher likelihood of entering a strategic alliance than low-quality companies, but they are also more likely to realize a successful exit. If this is the case, the coefficient on the alliance variable would be biased upwards. Therefore, we include company fixed effects in the next step to account for unobserved time invariant heterogeneity at the company level, such as factors that do not change over time, but that may affect the likelihood of an IPO or an M\&A and strategic alliance activity.

\subsection{Multinomial logit and survival models}

Pooled OLS and fixed effect estimations may raise three concerns. First, these models treat the decision to go public and the status of being public as if they were equal because we code the dependent variable as one in the year in which an exit occurred and in all following years. Second, they ignore the time lapse between the strategic alliance formation and the exit event. Third, we treat the IPO and M\&A exits independently because, in their respective analyses, we exclude companies that exited through the alternative channel (IPO or M\&A).

To account for these concerns, we run several additional analyses. We address the first and second concerns by estimating survival models. We specify an exponential survival distribution and include a frailty parameter in each model. To deal with the third concern, we estimate a multinomial logistic model for the entire panel of firms. In addition, we estimate a competing risk model (Fine and Gray 1999), which addresses all three concerns. 


\subsection{Matching}

One caveat in some prior studies is that they treat the formation of a strategic alliance as an exogenous event, though theory may suggest that it is a deliberate strategic choice by the VC firms and a way to bring about their proposed value-added. Since we want to draw causal inferences, we cannot ignore this inherent endogeneity. In contrast to previous empirical studies, we treat the decision for or against a strategic alliance as an endogenous strategic choice. We extend the ideas put forward in Hamilton and Nickerson (2003) by not only accounting for self-selection in strategic choices but also by modeling the alliance as a treatment effect.

We apply propensity score matching to deal with the potential self-selection. In our work, we followed prior empirical studies (Kaiser and Malchow-Møller 2011; Greene and Hopp 2017) who advised to employ different algorithms to map treatment and control observations to ensure sufficient matching precision on the propensity score. These methods trade estimation bias against estimation precision (variance). Based on observable characteristics, we match similar companies that have no strategic alliances to companies that have at least one strategic alliance (based on their predicted probability to enter an alliance). We estimate the propensity scores with a logistic regression and employ company and VC characteristics. More specifically, we include the founding year and the number of patents to control for similar company characteristics. Furthermore, we use the logs of the total number of involved VC firms, total VC rounds, and total VC amount to control for investment characteristics. Finally, we employ the average network of the participating VC firms to control for VC firm features. To construct the counterfactual outcome, we employ the kernel matching algorithm with 0.01 bandwidth. Then, we calculate the average treatment effect on the treated (ATT), which is the difference between the treatment and the control group.

Propensity score matching relies on two important assumptions. First, conditional independence $(\mathrm{CIA})$ requires that potential outcomes are independent of treatment assignment given a set of covariates $X$. Due to the potential for a dimensionality problem, we follow the approach in Rosenbaum and Rubin (1983) and use propensity scores as balancing scores. The second necessary assumption is the overlap condition or common support, which rules out the phenomenon of perfect predictability of the treatment indicator $D$ given the set of covariates $X$. We impose common support by dropping the treated observations with propensity scores that are above the maximum, or below the minimum values of the control observations.

The major drawback of propensity score matching is that one can only match on observable characteristics. The exclusion of unobservable characteristics can lead to biases if these characteristics influence the observed outcome and the treatment variable simultaneously. We conduct a sensitivity analysis to investigate how much variation in the unobserved variables can exist without impairing the result of the matching approach. We describe the procedure, which follows Rosenbaum (2002), Caliendo and Kopeinig (2008), and Aakvik (2001), in the Appendix. 


\section{Results}

\subsection{Full sample}

We start by reporting the results from the pooled OLS and fixed effect models. Panel A of Table 2 shows the results from the pooled OLS regressions with IPO exit as the dependent variable. In models (1) to (5), we use different measures to capture the strategic alliance activity. In the first two models, we focus on the alliance activity in the year prior to the exit. Both the number of strategic alliances (1) and the strategic alliance dummy (2) are positively related to IPO exit and the coefficient is statistically highly significant. Strategic alliance activity increases the IPO likelihood in the following year by 8.53 percentage points, and every strategic alliance is associated with a 5.19 percentage point increase in this likelihood. In models (3)-(5), instead of looking only at the year prior to the exit, we consider a five-year horizon. Models (3) and (4) capture the aggregate alliance activity within this horizon, which has a positive effect. Model (5) introduces a separate variable for each lag. We find the strongest effect in the year prior to the IPO. These results confirm the positive association between strategic alliance activity and IPOs.

In all regressions, we account for changes in economic conditions with time fixed effects. As control variables, we employ the number of VC rounds, number of VC firms, number of new investments, VC amount, VC network, and patents granted. The last two variables are based on the prior four years. Since we construct these variables from our database, the inclusion of four lags leads to a large drop in the number of observations. We deal with this issue in specifications (6) and (7), in which we construct our network and patent variable from the previous year's data and re-run models (1) and (2) with these two alternative control variables. Our results for the strategic alliance variables are similar. As to the control variables, we find that better networked VC firms and higher patenting activity are associated with a higher likelihood of IPOs. The definitions of all variables are in Table A1.

Panel $B$ depicts the results of the same models with M\&A exit as the dependent variable. Models (1) and (2) suggest a negative relationship between strategic alliance activity and M\&A exit in the subsequent year. When we consider a five-year horizon in models (3) and (4), the strategic alliance effect becomes insignificant. When we include the variables that count the number of strategic alliances in each year during the five-year horizon in model (5), we find a negative and significant effect in the year preceding the $M \& A$, consistent with the result in model (1). The effect stays negative in the years minus two and minus three, but it lacks significance. The coefficient sign changes in year minus four, in which it turns positive, and it becomes statistically significant in year minus five. These results suggest that the strategic alliance activity close to the M\&A event has a negative effect on the $M \& A$ exit, while earlier alliance activity (five years prior to the exit) has a positive effect.

When we estimate the same regressions for both types of exits with company fixed effects (see Table 3), the strategic alliance effects are approximately 2.3 to 2.5 times smaller for IPO exits (and not much different for M\&A exits). Strategic alliance activity increases the IPO likelihood in the following year by 3.3 percentage points, and every strategic alliance is associated with a 2.2 percentage point increase in this likelihood. In addition, we find positive and statistically significant effects in years minus two through 


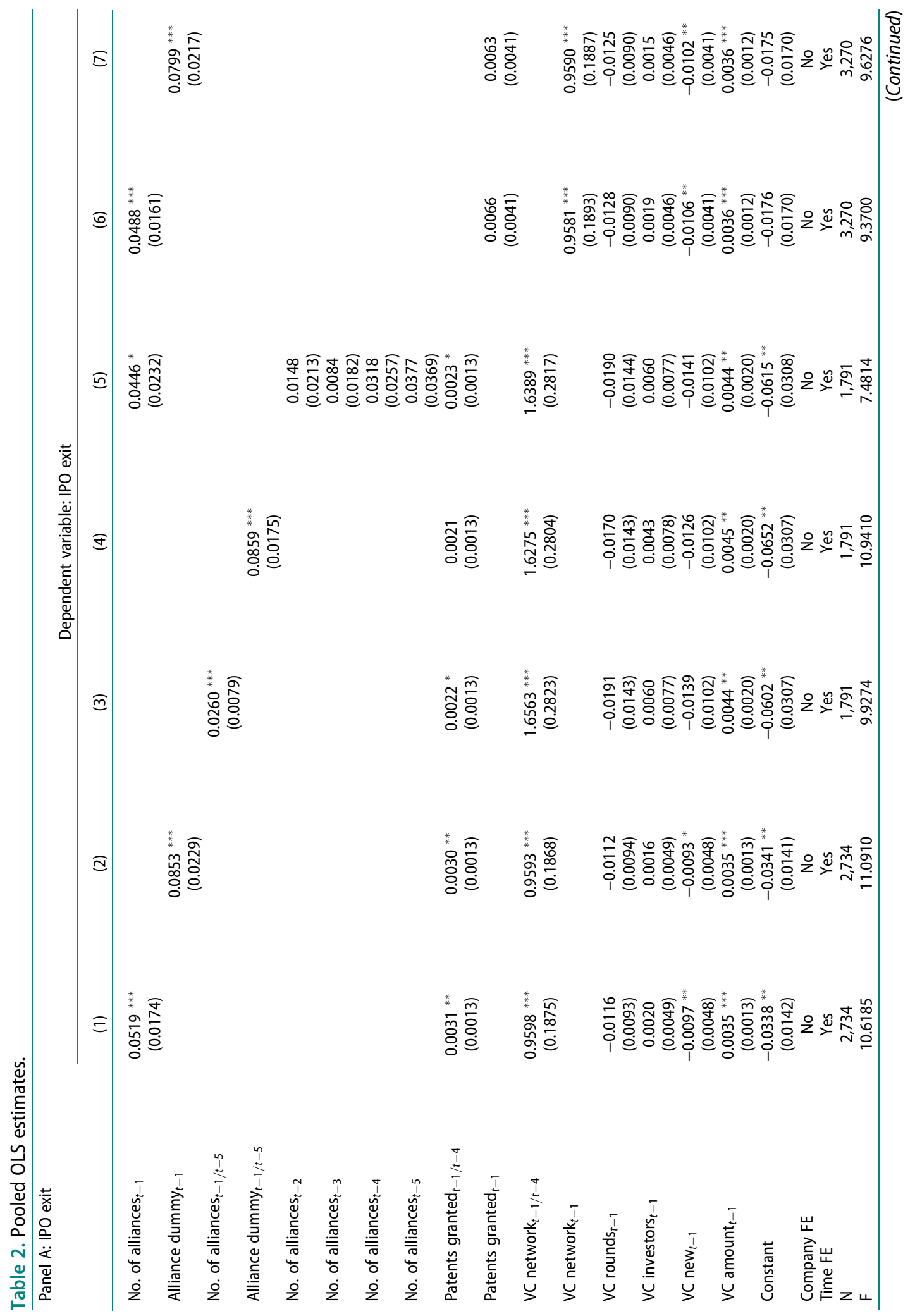




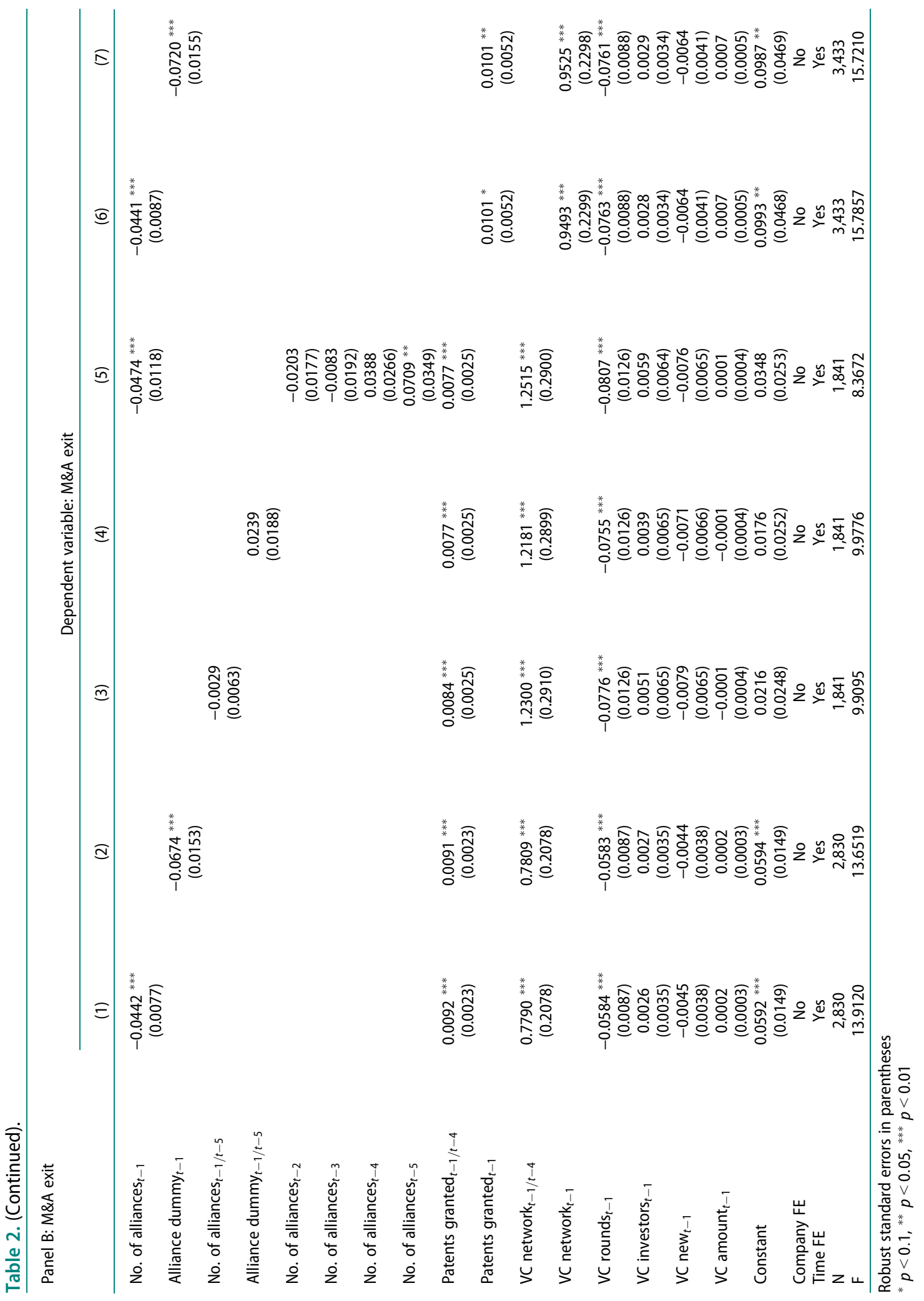




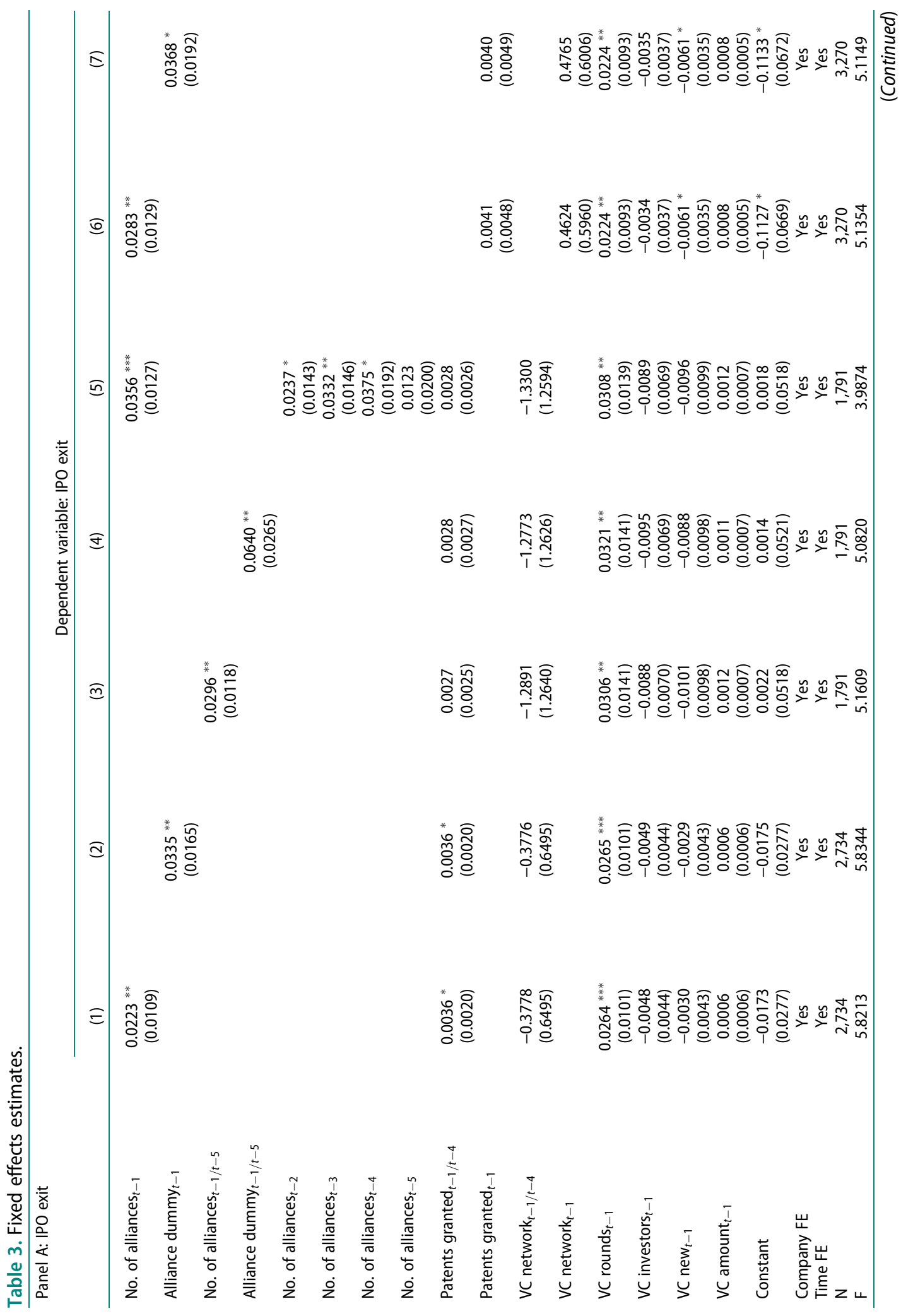




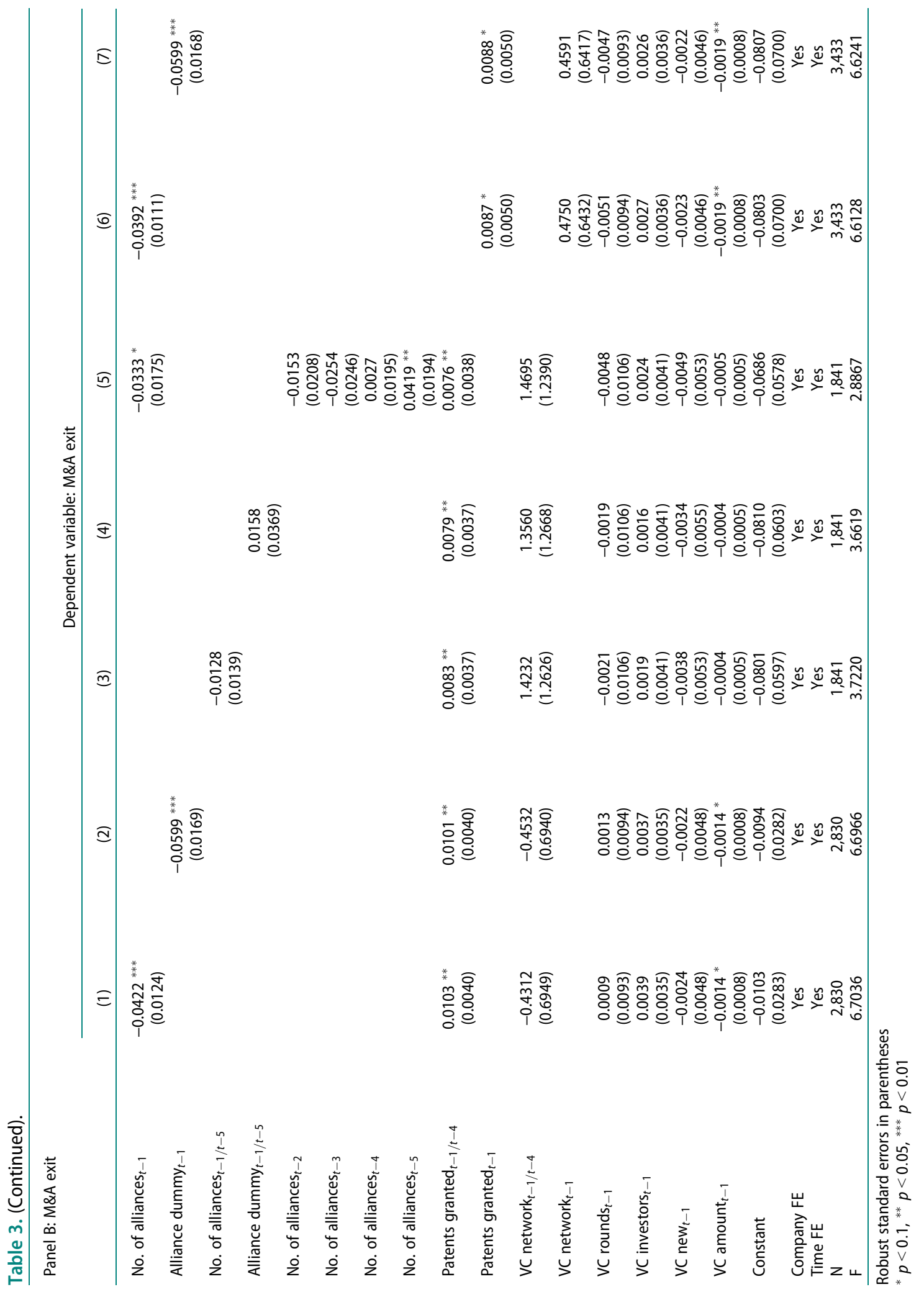


minus four. The effect of strategic alliances on M\&A activity is again insignificant over the five-year horizon, negative in year minus one, and positive in year minus five. Comparing these results with our findings in Table 2 suggests that the unobserved company characteristics associated with a higher likelihood to close a strategic alliance are at the same time positively linked to the likelihood of an IPO exit.

We proceed with the multinomial logit and survival models. ${ }^{3}$ The results from the multinomial logistic model with the entire panel of firms show that IPOs are more likely when there are more strategic alliances in the year before the IPO. In addition, strategic alliances in the year before an M\&A are negatively related to M\&As. The coefficient becomes positive in year minus three and significant at the $1 \%$ level in years minus four and minus five.

The results from the survival models are qualitatively similar. We find a positive relationship between the number of strategic alliances in the last five years and an IPO event. Each additional strategic alliance in the last five years increases the probability of an IPO by around $21 \%$ (p-value: 0.045 ). When we estimate the models for M\&A exit, we do not find that strategic alliance activity has a significant effect. The coefficient of the number of strategic alliances in the past five years is positive, but not significant (p-value: 0.427). Alternatively, we apply a competing-risks analysis, in which we define the time between the treatment and the event of interest as the time between the first strategic alliance and exit (IPO or M\&A). When we set the IPO as the event of interest and an $M \& A$ as the competing-risk event, the sub-hazard ratio (SHR) of the number of strategic alliances in the last five years is greater than one and statistically significant ( $p$-value: 0.016). Furthermore, when the $M \& A$ is the event of interest and the IPO is the competingrisk event, the effect of strategic alliances is statistically insignificant ( $p$-value $=0.402$ ) and the SHR is below one.

To summarize, all these results are consistent with the view that strategic alliances certify company quality for potential new buyers at the IPO exit, but not at the M\&A exit.

\subsection{Matching}

Panel A of Table 4 shows the ATT for companies that exited via an IPO. Companies with at least one strategic alliance have a 7.9 percentage point higher likelihood of an IPO than companies without a strategic alliance are in the matched sample. The difference is statistically significant with a t-value equal to 2.16 . The ATT is almost two times larger in the unmatched sample (17.5 percentage points), indicating that self-selection accounts for a sizeable part of the total effect. The table further shows that our matching approach was successful in reducing the standardized bias ${ }^{4}$ substantially. The balancing was successful because the mean bias was reduced from $37.9 \%$ before matching to $2.3 \%$ after matching, and the median bias decreased from $45.7 \%$ to $2.3 \%$. Moreover, after matching, the difference in the means of all variables between the treated and control groups is below $5 \%$ and is never statistically significant. For four out of the six variables we included in the matching procedure, we were able to reduce the bias by more than $92 \%$. In total, we included 564 companies in the analysis, where 12 untreated and 16 treated companies were outside the common support area and 353 untreated and 183 treated companies were in the support area.

Panel B summarizes the results for companies that exited through $M \& A$. The $A T T$ in the unmatched sample is 3.1 percentage points and after matching, it is down to 


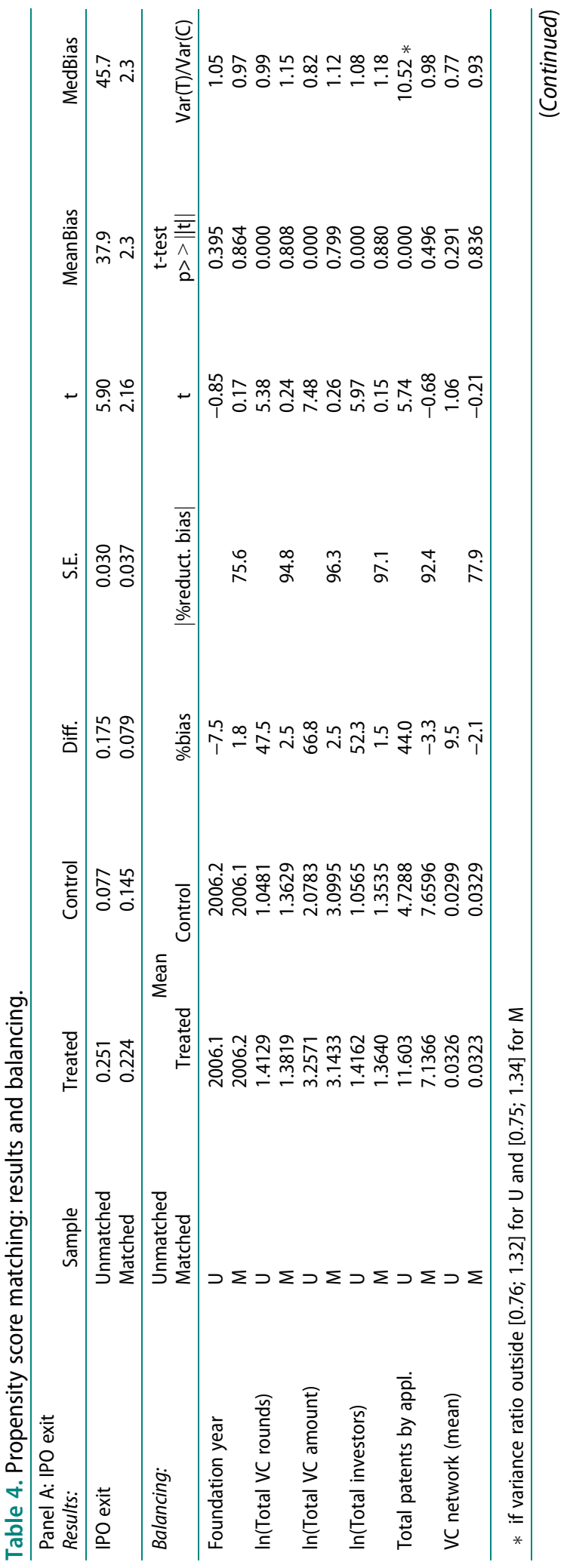




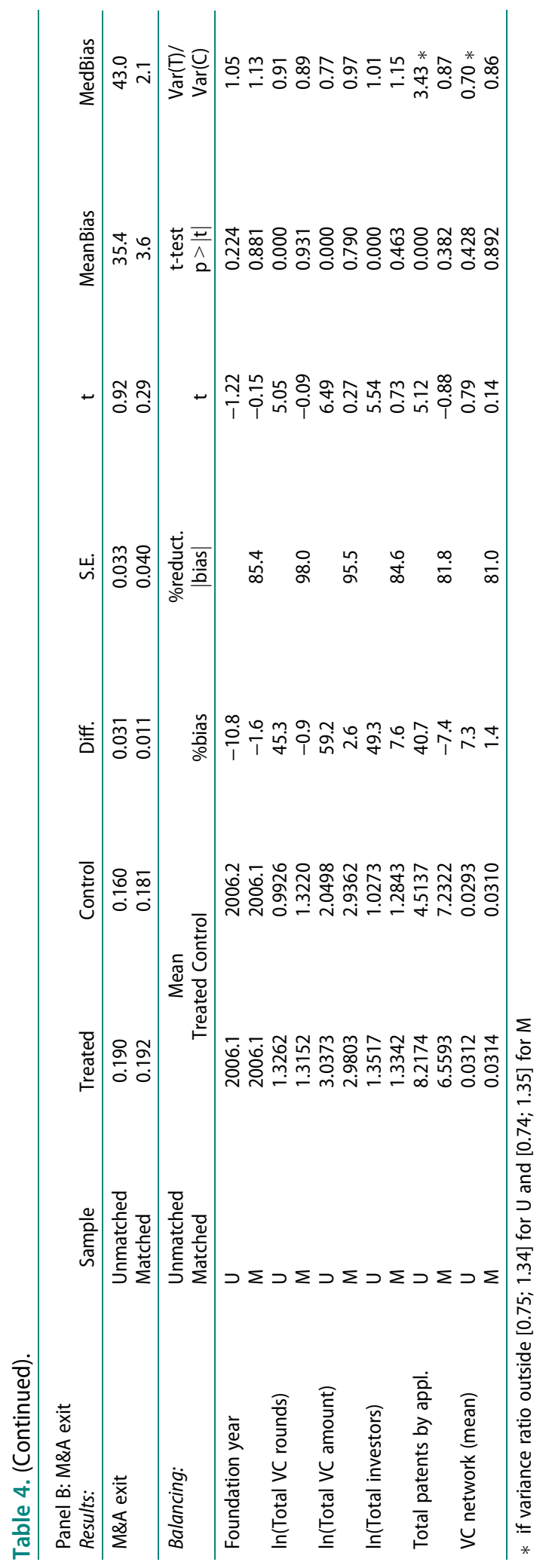


1.1 percentage points, both values are statistically insignificant. With matching, the mean bias drops from $35.4 \%$ to $3.6 \%$ and the median bias decreased from $43.0 \%$ to $2.1 \%$. Similar to Panel A, we were able to reduce a substantial part of the bias between the variables. In two out of the six variables, the mean bias is still above $5 \%$ (In(Total investors) and Total patents by appl.), but below $10 \%$. The difference in means after matching is always statistically insignificant. This part of the analysis included 567 companies; 390 untreated and 177 treated companies were inside the common support area.

Table 5 shows the results of the sensitivity check to analyze how much variation in the unobserved variables can exist without impairing the result of the matching approach. The first row reports the different values of the parameter Gamma $(\Gamma)$. This is equal to the odds of differential assignment due to unobserved factors. The values vary between 1 (the two observations have the same odds of receiving treatment and they do not differ in an unobserved way) and 2.5 (the observations could differ in their odds of receiving treatment by a factor of as much as 2.5). Rows 2-3 report the Mantel-Haenszel statistics under the assumption that the treatment effect is overestimated $\left(Q_{M H}^{+}\right)$or underestimated $\left(Q_{M H}^{-}\right)$. These rows show the results when the bounds of the test statistic move apart, and therefore indicate the sensitivity of the estimated treatment effect to unobserved bias. The last two rows report the significance levels for each test statistic. We can interpret the different bounds for the given values of $\Gamma$ as follows. If there is a positive unobserved self-selection; that is, when companies that are most likely to enter a strategic alliance also have a higher probability of having a successful exit, then the treatment effect is overestimated and the bounds of the test statistic must be adjusted downwards. If there is negative unobserved self-selection, meaning that the companies that are most likely to enter a strategic alliance have the lowest probability of having a successful exit, then the treatment effect is underestimated and the bounds must be adjusted upwards.

The overall conclusion from Table 5 is that the estimated treatment effect is not sensitive to unobserved bias up to a certain level. When $\Gamma$ increases to 2 , the test statistic $Q_{M H}^{+}$is significant at the $5 \%$ level ( $p$-value of 0.025 ) and for $\Gamma$ of 2.25 , it is still significant at the $10 \%$ level ( $p$-value of 0.065 ). That means that the odds of receiving treatment; that is, entering a strategic alliance, can differ between two companies up to $200 \%$ in an unobserved way, and we would still find a positive and significant treatment effect.

Table 5. Propensity score matching: sensitivity analysis.

\begin{tabular}{llllllcc}
\hline Gamma & \multicolumn{1}{c}{1} & \multicolumn{1}{c}{1.25} & \multicolumn{1}{c}{1.5} & \multicolumn{1}{c}{1.75} & \multicolumn{1}{c}{2} & 2.25 & 2.5 \\
\hline$Q_{M H}^{+}$ & 4.7259 & 3.8091 & 3.0805 & 2.4778 & 1.9634 & 1.5144 & 1.1155 \\
$Q_{M H}^{-}$ & 4.7259 & 5.6929 & 6.5177 & 7.2470 & 7.9061 & 8.5112 & 9.0731 \\
$p_{M H}^{+}$ & $1.10 \mathrm{E}-06$ & 0.0000 & 0.0010 & 0.0066 & 0.0248 & 0.0650 & 0.1323 \\
$p_{M H}^{-}$ & $1.10 \mathrm{E}-06$ & $6.20 \mathrm{E}-09$ & $3.60 \mathrm{E}-11$ & $2.10 \mathrm{E}-13$ & $1.30 \mathrm{E}-15$ & 0 & 0
\end{tabular}

Gamma: odds of differential assignment due to unobserved factors

$Q_{M H}^{+}:$Mantel-Haenszel statistic (assumption: overestimation of treatment effect)

$Q_{M H}^{-}$: Mantel-Haenszel statistic (assumption: underestimation of treatment effect)

$p_{M H}^{+}$: significance level (assumption: overestimation of treatment effect)

$p_{M H}^{-}$: significance level (assumption: underestimation of treatment effect) 


\subsection{Robustness}

To account for the potential problems of right censoring, we perform an additional analysis in which we exclude all companies that obtained a VC round in the last two years of our sample period (2013 and 2014) because it is likely that these companies will realize a successful exit in the following years. The analysis confirms our main results; the effects are slightly stronger (see Table 6).

Regarding the censoring problem in the propensity score matching, we also apply propensity score matching on the reduced sample, in which we exclude companies that received a VC round in 2013 or 2014. The difference in the unmatched sample for IPO exits is 20.1 percentage points (t-value: 5.80 ) and for M\&A exits, 6.1 percentage points (t-value: 1.27). The ATT is still much lower after matching. The treatment effect on IPOs decreases to 13.8 percentage points ( $t$-value: 2.89 ) and to 1.7 percentage points (t-value: 0.29 ) for M\&A exits. The mean bias is $4.8 \%$ and $5.6 \% .^{5}$

After matching, we can also control for unobserved and observed heterogeneity and censoring. Table 7 shows the results for models that correspond to those in Table 6 but are based only on the matched sample. Consistent with the prior results, we find positive and statistically significant effects of strategic alliance activity within the fiveyear horizon preceding the exit for IPOs, but not for M\&As. The effect is positive for years minus one through minus three for IPOs, negative for year minus one, and positive for year minus five for M\&As. The statistical and economic significance of the strategic alliance variables are smaller, indicating, again, that self-selection is a relevant issue.

We also test alternative matching approaches to ensure that our results are not driven by the choice of matching algorithm. More specifically, we apply 1, 2, 5, and 10-nearest neighbors matching, radius matching with different specified radii, trimming, and kernel matching with different bandwidths. The estimates of the ATT do not differ much (see Table 8). In particular, the treatment effect for IPOs varies between $6.8 \%$ and $10.7 \%$. The treatment effect for M\&As remains insignificant within the matched sample and ranges between $-2.4 \%$ and $2.8 \%$. We estimate multivariate regressions from Table 7 with these different samples, and the main conclusions remain the same.

\section{Discussion and conclusion}

In this work, we analyze the impact of strategic alliances on VC exits. We explicitly ask whether strategic alliances may serve as a device that certifies companies' quality towards potential new investors and whether this potential certification role differs in different exit channels (IPO vs. M\&A).

We deliver two main results. First, the effects of alliances on the likelihood of a successful exit are lower than those reported in prior studies such as those by Ozmel, Robinson, and Stuart (2013) or Qi, Sutton, and Zheng (2015). The comparison of the results between various model specifications leads us to the conclusion that prior results tend to be biased without endogeneity corrections, particularly if one does not account for selfselection into the strategic alliance activity and the presence of unobserved heterogeneity. Second, our findings suggest that alliances improve the probability of successful IPOs, but not M\&As. 


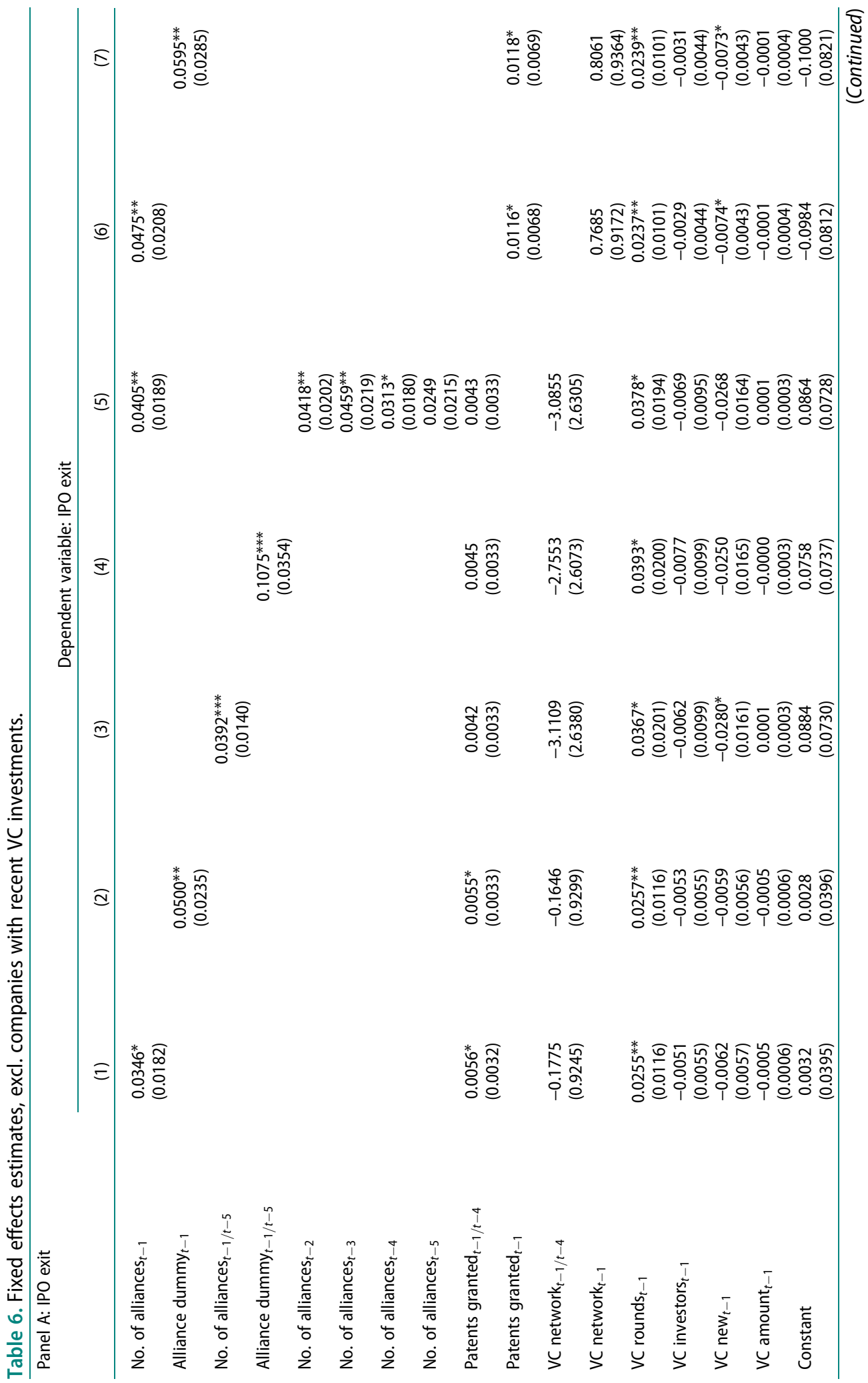


VENTURE CAPITAL

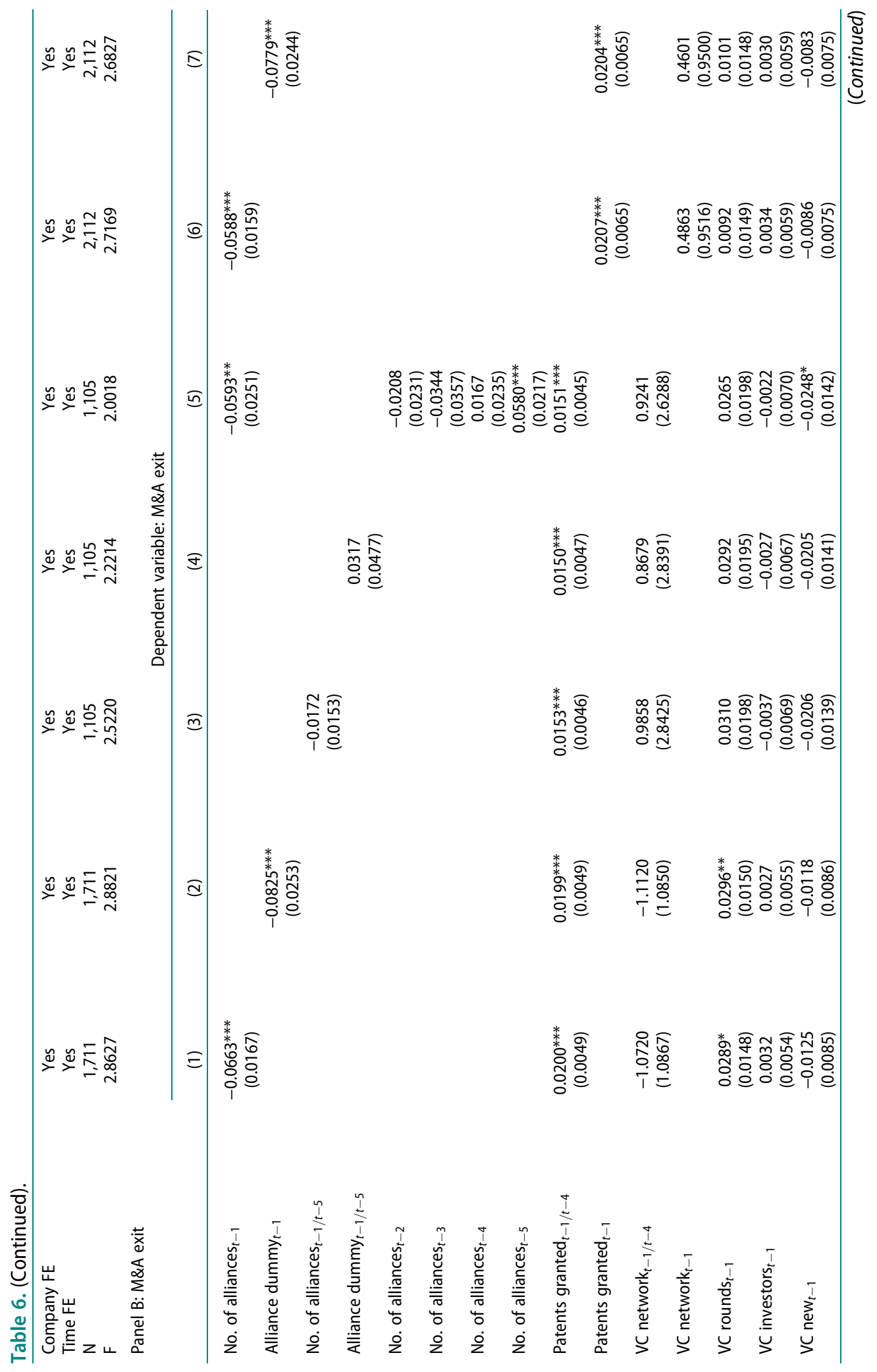




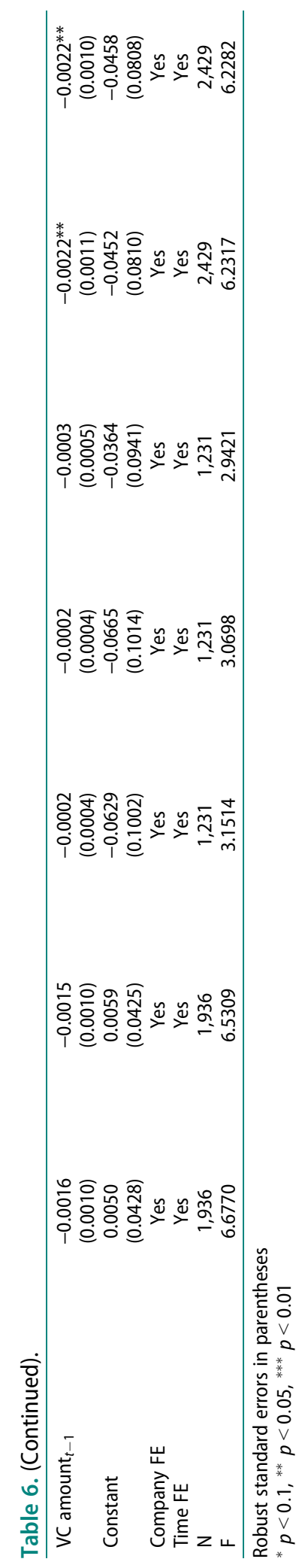




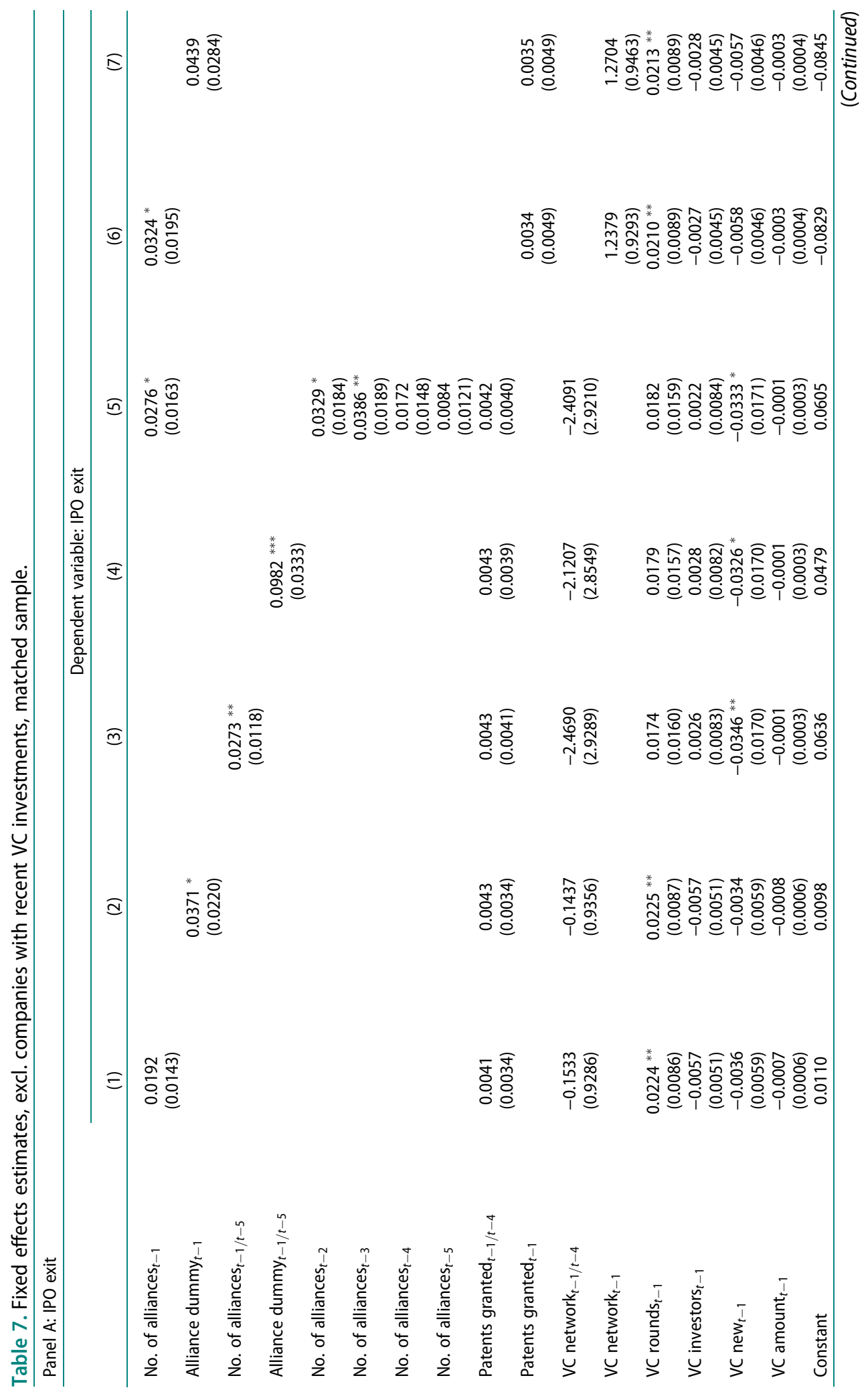




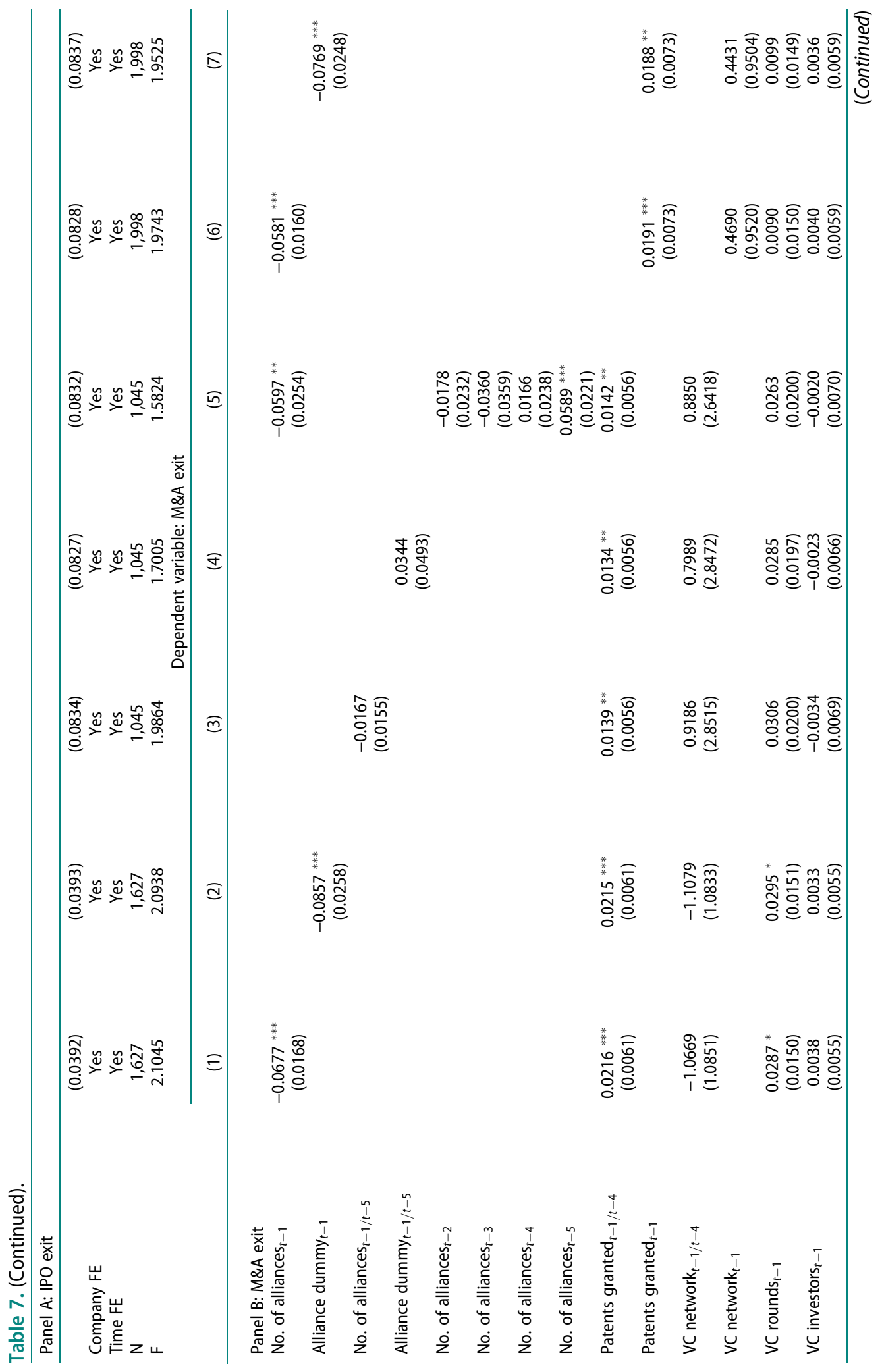




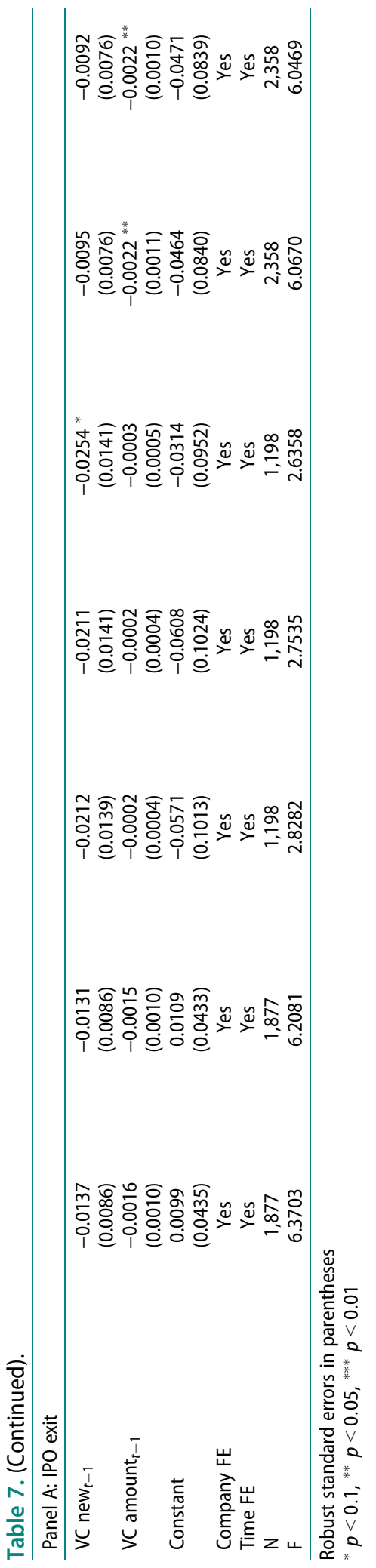


Table 8. Propensity score matching: Robustness of ATT.

\begin{tabular}{|c|c|c|c|c|c|c|c|c|}
\hline & \multirow[b]{2}{*}{ Matching algorithm } & \multicolumn{2}{|c|}{ Mean } & \multirow[b]{2}{*}{ Difference } & \multirow[b]{2}{*}{ S.E. } & \multirow[b]{2}{*}{$\mathrm{t}$} & \multicolumn{2}{|c|}{ Bias } \\
\hline & & Treated & Controls & & & & Mean & Median \\
\hline \multirow[t]{14}{*}{ IPO exit } & Baseline: Kernel (0.01) & 0.224 & 0.145 & 0.079 & 0.037 & 2.16 & 2.3 & 2.3 \\
\hline & Kernel (0.05) & 0.241 & 0.151 & 0.089 & 0.036 & 2.49 & 2.4 & 2.4 \\
\hline & Kernel (0.1) & 0.241 & 0.148 & 0.093 & 0.036 & 2.60 & 2.9 & 2.9 \\
\hline & 1-nearest neighbor & 0.241 & 0.141 & 0.099 & 0.046 & 2.17 & 5.8 & 5.3 \\
\hline & 2-nearest neighbors & 0.241 & 0.144 & 0.097 & 0.042 & 2.31 & 5.2 & 4.6 \\
\hline & 5-nearest neighbors & 0.241 & 0.156 & 0.085 & 0.038 & 2.25 & 3.0 & 2.4 \\
\hline & 10-nearest neighbors & 0.241 & 0.152 & 0.088 & 0.037 & 2.41 & 1.6 & 1.8 \\
\hline & Caliper (0.1) & 0.241 & 0.141 & 0.099 & 0.046 & 2.17 & 5.8 & 5.3 \\
\hline & Caliper (0.05) & 0.241 & 0.141 & 0.099 & 0.046 & 2.17 & 5.8 & 5.3 \\
\hline & Caliper (0.01) & 0.224 & 0.142 & 0.082 & 0.046 & 1.78 & 4.7 & 3.9 \\
\hline & Caliper (0.001) & 0.175 & 0.100 & 0.075 & 0.048 & 1.57 & 7.3 & 6.0 \\
\hline & Trimming (10) & 0.206 & 0.128 & 0.078 & 0.047 & 1.67 & 5.0 & 4.0 \\
\hline & Trimming (5) & 0.237 & 0.168 & 0.068 & 0.047 & 1.44 & 2.2 & 1.3 \\
\hline & Trimming (1) & 0.245 & 0.138 & 0.107 & 0.048 & 2.24 & 7.4 & 6.7 \\
\hline \multirow[t]{14}{*}{$M \& A$ exit } & Baseline: Kernel (0.01) & 0.192 & 0.181 & 0.011 & 0.040 & 0.29 & 3.6 & 2.1 \\
\hline & Kernel (0.05) & 0.190 & 0.166 & 0.024 & 0.037 & 0.65 & 2.6 & 2.0 \\
\hline & Kernel (0.1) & 0.193 & 0.169 & 0.024 & 0.037 & 0.65 & 2.9 & 2.1 \\
\hline & 1-nearest neighbor & 0.193 & 0.199 & -0.006 & 0.050 & -0.11 & 5.6 & 5.7 \\
\hline & 2-nearest neighbors & 0.193 & 0.166 & 0.028 & 0.043 & 0.64 & 5.9 & 5.0 \\
\hline & 5-nearest neighbors & 0.193 & 0.177 & 0.017 & 0.040 & 0.41 & 1.7 & 1.9 \\
\hline & 10 -nearest neighbors & 0.193 & 0.172 & 0.021 & 0.039 & 0.54 & 2.0 & 1.9 \\
\hline & Caliper (0.1) & 0.193 & 0.199 & -0.006 & 0.050 & -0.11 & 5.6 & 5.7 \\
\hline & Caliper (0.05) & 0.190 & 0.201 & -0.011 & 0.050 & -0.22 & 5.5 & 6.1 \\
\hline & Caliper (0.01) & 0.192 & 0.203 & -0.011 & 0.050 & -0.22 & 5.4 & 6.2 \\
\hline & Caliper (0.001) & 0.219 & 0.203 & 0.016 & 0.055 & 0.28 & 6.6 & 8.1 \\
\hline & Trimming (10) & 0.192 & 0.217 & -0.024 & 0.053 & -0.45 & 6.5 & 6.0 \\
\hline & Trimming (5) & 0.194 & 0.206 & -0.011 & 0.052 & -0.22 & 5.3 & 5.9 \\
\hline & Trimming (1) & 0.191 & 0.197 & -0.005 & 0.051 & -0.11 & 5.4 & 6.3 \\
\hline
\end{tabular}

In the unmatched sample, we find that companies that entered at least one strategic alliance have a 17.5 percentage point higher likelihood of an IPO than their peers without any strategic alliance activity. Exit through M\&As is 3.1 percentage points more likely (but not statistically significant) if companies engaged in strategic alliances in the past. However, after controlling for observed and unobserved heterogeneity, self-selection, and censoring, we conclude that the effect of strategic alliances is less than what a simple comparison revealed. Companies that entered into at least one strategic alliance in the five-year period prior to exit realized a 9.8 percentage point higher likelihood of an IPO, while the aggregate effect (over 5 years) on M\&As remains insignificant.

We demonstrate that strategic alliances are associated with a higher likelihood of an IPO. Furthermore, our findings indicate that M\&As are less likely when firms make recent alliances. The time pattern is interesting: The first three lags of the number of strategic alliances have a negative effect on the M\&A likelihood, though only the first lag is significant. The strategic alliance effect becomes positive starting with the fourth lag, and turns statistically significant with the fifth lag. Our interpretation is that strategic alliances increase the likelihood of M\&As when the company did not have an opportunity to go public. This conclusion is supported when we look at the average time to exit, which is significantly shorter for IPOs than for M\&As. 


\subsection{Theoretical and practical implications}

Our work extends prior research in the entrepreneurial finance domain (Tykvová (2018) for a recent survey). Our findings expand the knowledge on the role of alliances in VC financing by providing a more accurate estimate of the actual impact of alliances on exists and contextualize prior findings and their corresponding boundary conditions. Our study therefore provides new grounds to consider the heterogeneity of VC targets and the heterogeneity in their organizational development trajectories (see AlvarezGarrido and Dushnitsky 2016). Our work more broadly also contributes to research on entrepreneurial resource acquisition by showing that when VC firms and other incumbents aim to exit their financed ventures, strategic alliances may provide valuable information for potential buyers in an IPO process. We add the empirical observation that certification effects are more relevant in IPOs. Strategic alliances seem to certify good quality and promote quicker paths to IPOs. Yet, we also add to the literature on third-party signals, that such alliances do not lead to quicker M\&As because before an $M \& A$, an interested buyer performs due diligence and a certification device may not provide much additional information in the course of an M\&A. This supports prior findings that direct ties, such as alliances, facilitate quality assessments (Jääskeläinen and Maula 2014) and that when faced with widely dispersed external parties, such as IPO investors, third-party affiliations are helpful for ventures when seeking external capital because these affiliations certify the quality of the new venture (Plummer, Allison, and Connelly 2016).

Lastly, our results have implications not only for academic research but also for entrepreneurs, VC firms, and potential new buyers, which should be aware of the implications of strategic alliances. According to Giot and Schwienbacher (2007) and Black and Gilson (1998), IPOs are the preferred exit choice for VC firms. Therefore, VC firms might increase their chances of taking their companies public with their portfolio company by promoting and encouraging strategic alliances. Engaging in strategic alliances early might help to spur firm growth, provide quick access to clients, and might help to leverage resources that otherwise would take a long time to develop alone. As such, entrepreneurs should develop strategic goals and visions around their partnering and alliance activities.

\subsection{Limitations and avenues for future research}

Our study has limitations that call for future research. We explicitly control for observed and unobserved heterogeneity in our cohort sample, alleviate concerns relating to selfselection into alliance activity, and assuage methodological concerns with respect to censoring. That is, while we can eliminate a number of endogeneity issues, there is still a potential risk from unobserved characteristics that vary over time, such as management performance or the ability of the entrepreneurs and company owners. Future research along these lines might first want to theorize more about the underlying drivers of both alliances and exit channels to help subsequently study how the potential antecedents impact the alliance activity and, in turn, affect exit strategies. This could help in exploring a mediation perspective of strategic alliances in pursuit of the exit goal. 
In addition, we cannot observe the true motivation of entrepreneurs when they choose to enter a strategic alliance. This can lead to biased results in the propensity score matching, in which we match treated and untreated companies based on observed characteristics. While we find that our results are not susceptible to potential omitted confounders, future research might want to investigate this area further. For example, survey designs could shed more light on what drives young companies to enter a strategic alliance. For example, researchers could analyze the role of VC firm networks and connections to prior syndication partners in promoting strategic alliances.

Future work could have a closer look as to why the effect of strategic alliances on IPOs and $M \& A s$ differs. This is especially important as trade-offs faced in the exit process might be related to prior decisions taken by the VC firm during the early stages of the financing of the venture. For instance, it might be worthwhile to explore the role of complementary resources and the synergies leveraged among the financed firm and the corresponding alliance partner to better understand when alliances lead to IPOs or M\&As (AlvarezGarrido and Dushnitsky 2016; Guo, Lou, and Pérez-Castrillo 2015).

Furthermore, we find ambiguous results for the role of strategic alliances in the M\&A process. We showed that recent strategic alliances are negatively related to M\&As on average, but the effect is not constant over the firm life-cycle. There might be other reasons that companies enter strategic alliances, such as an expansion to international markets. Along these lines, we assumed alliances partners to be similar across our sample studied. Clearly, the prominence of the alliance partners can have important effects and might result in stronger signaling effects for some firms but not others (Stuart, Hoang, and Hybels 1999; Stuart 2000). Similarly, it might be fruitful to study the point of time at which the companies choose strategic alliances.

Finally, one also needs to be cognizant about the context of our findings to better understand the generalizability of our results. We show that alliances interact with exits in a complex way. While (recent) alliances positively affect IPOs, the effect we find is lower compared to what previous studies conclude. Yet our analysis shows the importance of strategic alliances and their role as a certification device for VC-backed biotechnology companies only. It is important to acknowledge that biotechnology is a peculiar industry as alliances often also represent major funding sources and are therefore more important milestones than in other industries (Lerner, Shane, and Tsai 2003; Robinson and Stuart 2007a). Along these lines, our findings might be context specific. We would therefore invite future research studying the role of alliances in more high-tech vs. more low-tech industries to uncover potential moderating effects of the direct relation between alliances and exits studied in our work.

\section{Notes}

1. We explicitly exclude joint ventures and other business relationships such as licensing, distribution, or franchising. Some other commercial databases have different definitions of strategic alliances that also include stakeholder alliances such as cooperation with suppliers or customers, as strategic alliances.

2. We use a linear probability model because non-linear models have several disadvantages such as neglected heterogeneity, heteroscedasticity, and non-normality in the latent variable model or a possible incidental parameter problem. Because we are interested in average 
marginal effects, linear regressions are reasonable in this context (see, e.g., pp. 563, 583, 599-604, 619-625: Wooldridge 2010).

3. We do not present the results here, but they are available from the authors upon request.

4. We calculate the standardized bias following Rosenbaum and Rubin (1985).

5. We do not present the results here, but they are available from the authors upon request.

6. A classic example for such an unobserved bias would be motivation. In that case, the dummy variable equals one if the founder of the company is motivated and zero otherwise.

\section{Acknowledgments}

We are grateful for the access to Thomson One, Dow Jones VentureSource, S\&P Capital IQ, and Patstat provided by the Hohenheim Datalab. Our special thanks goes to Vincenzo Capizzi for helpful conversation and feedback. We also thank Diego D'Adda, Anaïs Hamelin, Allan Riding, and Vikram Nanda for valuable comments. We presented earlier drafts of this work at the Academy of Entrepreneurial Finance Conference (2017), at the Augustin Cournot Doctoral Days (2017), Emerging Trends in Entrepreneurial Finance Conference (2017), and the Entrepreneurial Finance Conference (2018).

\section{Disclosure statement}

No potential conflict of interest was reported by the author(s).

\section{References}

Aakvik, A. 2001. "Bounding a Matching Estimator: The Case of a Norwegian Training Program." Oxford Bulletin of Economics and Statistics 63 (1): 115-143. doi:10.1111/1468-0084.00211.

Alexander, C., and D. Cumming. 2020. Corruption and Fraud in Financial Markets: Malpractice, Misconduct and Manipulation. Hoboken, NJ: John Wiley \& Sons.

Allen, F., and G. R. Faulhaber. 1989. "Signalling by Underpricing in the Ipo Market." Journal of Financial Economics 23 (2): 303-323. doi:10.1016/0304-405X(89)90060-3.

Alvarez-Garrido, E., and G. Dushnitsky. 2016. "Are Entrepreneurial Venture's Innovation Rates Sensitive to Investor Complementary Assets? Comparing Biotech Ventures Backed by Corporate and Independent Vcs." Strategic Management Journal 37 (5): 819-834. doi:10.1002/ smj.2359.

Anand, B. N., and T. Khanna. 2000. "Do Firms Learn to Create Value? The Case of Alliances." Strategic Management Journal 21: 295-315. doi:10.1002/(SICI)1097-0266(200003)21:3<295::AID-SMJ91>3. 0.CO;2-O.

Basdeo, D. K., K. G. Smith, C. M. Grimm, V. P. Rindova, and P. J. Derfus. 2006. "The Impact of Market Actions on Firm Reputation." Strategic Management Journal 27 (12): 1205-1219. doi:10.1002/ smj.556.

Black, B. S., and R. J. Gilson. 1998. "Venture Capital and the Structure of Capital Markets: Banks versus Stock Markets." Journal of Financial Economics 47 (3): 243-277. doi:10.1016/S0304-405X(97) 00045-7.

Bushman, R. M., J. D. Piotroski, and A. J. Smith. 2004. "What Determines Corporate Transparency?" Journal of Accounting Research 42 (2): 207-252. doi:10.1111/j.1475-679X.2004.00136.x.

Caliendo, M., and S. Kopeinig. 2008. "Some Practical Guidance for the Implementation of Propensity Score Matching." Journal of Economic Surveys 22 (1): 31-72. doi:10.1111/j.1467-6419.2007.00527.x.

Chen, G., D. C. Hambrick, and T. G. Pollock. 2008. "Puttin'on the Ritz: Pre-ipo Enlistment of Prestigious Affiliates as Deadline-induced Remediation." Academy of Management Journal 51 (5): 954-975. doi:10.5465/amj.2008.34789666.

Cumming, D. 2008. "Contracts and Exits in Venture Capital Finance." Review of Financial Studies 21 (5): 1947-1982. doi:10.1093/rfs/hhn072. 
Cumming, D., and S. Johan. 2008. "Information Asymmetries, Agency Costs and Venture Capital Exit Outcomes." Venture Capital 10 (3): 197-231. doi:10.1080/13691060802151788.

Dai, N., H. Jo, and S. Kassicieh. 2012. “Cross-border Venture Capital Investments in Asia: Selection and Exit Performance." Journal of Business Venturing 27 (6): 666-684. doi:10.1016/j. jbusvent.2011.04.004.

Daily, C. M., S. T. Certo, D. R. Dalton, and R. Roengpitya. 2003. “Ipo Underpricing: A Meta-analysis and Research Synthesis." Entrepreneurship Theory and Practice 27 (3): 271-295. doi:10.1111/1540-8520. t01-1-00004.

Das, S. R., H. Jo, and Y. Kim. 2011. "Polishing Diamonds in the Rough: The Sources of Syndicated Venture Performance." Journal of Financial Intermediation 20 (2): 199-230. doi:10.1016/j. ji. 2010.08.001.

Deeds, D. L., D. Decarolis, and J. E. Coombs. 1997. "The Impact of Firmspecific Capabilities on the Amount of Capital Raised in an Initial Public Offering: Evidence from the Biotechnology Industry." Journal of Business Venturing 12 (1): 31-46. doi:10.1016/S0883-9026(97)84970-1.

Fine, J. P., and R. J. Gray. 1999. "A Proportional Hazards Model for the Subdistribution of A Competing Risk." Journal of the American Statistical Association 94 (446): 496-509. doi:10.1080/01621459.1999.10474144.

Giot, P., and A. Schwienbacher. 2007. "Ipos, Trade Sales and Liquidations: Modelling Venture Capital Exits Using Survival Analysis." Journal of Banking \& Finance 31 (3): 679-702. doi:10.1016/j. jbankfin.2006.06.010.

Greene, F. J., and C. Hopp. 2017. "Are Formal Planners More Likely to Achieve New Venture Viability? A Counterfactual Model and Analysis." Strategic Entrepreneurship Journal 11 (1): 36-60. doi:10.1002/sej.1245.

Guo, B., Y. Lou, and D. Pérez-Castrillo. 2015. "Investment, Duration, and Exit Strategies for Corporate and Independent Venture Capital-backed Start-ups." Journal of Economics \& Management Strategy 24 (2): 415-455. doi:10.1111/jems.12097.

Hagedoorn, J., and B. Sadowski. 1999. "The Transition from Strategic Technology Alliances to Mergers and Acquisitions: An Exploratory Study." Journal of Management Studies 36 (1): 87-107. doi:10.1111/1467-6486.00127.

Hamilton, B. H., and J. A. Nickerson. 2003. "Correcting for Endogeneity in Strategic Management Research." Strategic Organization 1 (1): 51-78. doi:10.1177/1476127003001001218.

Hochberg, Y. V. 2012. "Venture Capital and Corporate Governance in the Newly Public Firm." Review of Finance 16 (2): 429-480. doi:10.1093/rof/rfr035.

Hochberg, Y. V., A. Ljungqvist, and Y. Lu. 2007. "Whom You Know Matters: Venture Capital Networks and Investment Performance." The Journal of Finance 62 (1): 251-301. doi:10.1111/j.15406261.2007.01207.x.

Hoenig, D., and J. Henkel. 2015. "Quality Signals? The Role of Patents, Alliances, and Team Experience in Venture Capital Financing." Research Policy 44 (5): 1049-1064. doi:10.1016/j. respol.2014.11.011.

Jääskeläinen, M., and M. Maula. 2014. "Do Networks of Financial Intermediaries Help Reduce Local Bias? Evidence from Cross-border Venture Capital Exits." Journal of Business Venturing 29 (5): 704-721. doi:10.1016/j.jbusvent.2013.09.001.

Kaiser, U., and N. Malchow-Møller. 2011. "Is Self-employment Really a Bad Experience?: The Effects of Previous Self-employment on Subsequent Wage-employment Wages." Journal of Business Venturing 26 (5): 572-588. doi:10.1016/j.jbusvent.2010.02.001.

Lee, P. M., and S. Wahal. 2004. "Grandstanding, Certification and the Underpricing of Venture Capital Backed Ipos." Journal of Financial Economics 73 (2): 375-407. doi:10.1016/j. jfineco.2003.09.003.

Lerner, J., H. Shane, and A. Tsai. 2003. "Do Equity Financing Cycles Matter? Evidence from Biotechnology Alliances." Journal of Financial Economics 67 (3): 411-446. doi:10.1016/50304405X(02)00256-8.

Lindsey, L. 2008. "Blurring Firm Boundaries: The Role of Venture Capital in Strategic Alliances." The Journal of Finance 63 (3): 1137-1168. doi:10.1111/j.1540-6261.2008.01354.x. 
Mantel, N., and W. Haenszel. 1959. "Statistical Aspects of the Analysis of Data from Retrospective Studies of Disease." Journal of the National Cancer Institute 22 (4): 719-748.

Megginson, W. L., and K. A. Weiss. 1991. "Venture Capitalist Certification in Initial Public Offerings." The Journal of Finance 46 (3): 879-903. doi:10.1111/j.1540-6261.1991.tb03770.x.

Milgrom, P., and J. Roberts. 1986. "Price and Advertising Signals of Product Quality." Journal of Political Economy 94 (4): 796-821. doi:10.1086/261408.

Nahata, R. 2008. "Venture Capital Reputation and Investment Performance." Journal of Financial Economics 90 (2): 127-151. doi:10.1016/j.jineco.2007.11.008.

Nahata, R., S. Hazarika, and K. Tandon. 2014. "Success in Global Venture Capital Investing: Do Institutional and Cultural Differences Matter?" Journal of Financial and Quantitative Analysis 49 (4): 1039-1070. doi:10.1017/S0022109014000568.

Ozmel, U., D. T. Robinson, and T. E. Stuart. 2013. "Strategic Alliances, Venture Capital, and Exit Decisions in Early Stage High-tech Firms." Journal of Financial Economics 107 (3): 655-670. doi:10.1016/j.jineco.2012.09.009.

Plummer, L. A., T. H. Allison, and B. L. Connelly. 2016. “Better Together? Signaling Interactions in New Venture Pursuit of Initial External Capital." Academy of Management Journal 59 (5): 1585-1604. doi:10.5465/amj.2013.0100.

Qi, J., N. K. Sutton, and Q. Zheng. 2015. "The Value of Strategic Alliances in Acquisitions and Ipos." Financial Management 44 (2): 387-430. doi:10.1111/fima.12040.

Robinson, D. T., and T. E. Stuart. 2007a. "Financial Contracting in Biotech Strategic Alliances." Journal of Law and Economics 50 (3): 559-596. doi:10.1086/519811.

Robinson, D. T., and T. E. Stuart. 2007b. "Network Effects in the Governance of Strategic Alliances." Journal of Law, Economics, and Organization 23 (1): 242-273. doi:10.1093/jleo/ewm010.

Rosenbaum, P. R. 2002. Observational Studies. New York, NY: Springer.

Rosenbaum, P. R., and D. B. Rubin. 1983. "The Central Role of the Propensity Score in Observational Studies for Causal Effects." Biometrika 70 (1): 41-55. doi:10.1093/biomet/70.1.41.

Rosenbaum, P. R., and D. B. Rubin. 1985. "Constructing a Control Group Using Multivariate Matched Sampling Methods that Incorporate the Propensity Score." The American Statistician 39 (1): 33-38.

Sørensen, M. 2007. "How Smart Is Smart Money? A Two-sided Matching Model of Venture Capital." The Journal of Finance 62 (6): 2725-2762. doi:10.1111/j.1540-6261.2007.01291.x.

Stuart, T. E. 1998. "Network Positions and Propensities to Collaborate: An Investigation of Strategic Alliance Formation in a High-technology Industry." Administrative Science Quarterly 43: 668-698. doi:10.2307/2393679.

Stuart, T. E. 2000. "Interorganizational Alliances and the Performance of Firms: A Study of Growth and Innovation Rates in A High-technology Industry." Strategic Management Journal 21 (8): 791-811. doi:10.1002/1097-0266(200008)21:8<791::AID-SMJ121>3.0.CO;2-K.

Stuart, T. E., H. Hoang, and R. C. Hybels. 1999. "Interorganizational Endorsements and the Performance of Entrepreneurial Ventures." Administrative Science Quarterly 44 (2): 315-349. doi:10.2307/2666998.

Tykvová, T. 2018. "Venture Capital and Private Equity Financing: An Overview of Recent Literature and an Agenda for Future Research." Journal of Business Economics 88 (3-4): 325-362.

Wang, H., R. J. Wuebker, S. Han, and M. D. Ensley. 2012. "Strategic Alliances by Venture Capital Backed Firms: An Empirical Examination." Small Business Economics 38 (2): 179-196. doi:10.1007/ s11187-009-9247-x.

Welch, I. 1989. "Seasoned Offerings, Imitation Costs, and the Underpricing of Initial Public Offerings." The Journal of Finance 44 (2): 421-449. doi:10.1111/j.1540-6261.1989.tb05064.x.

Wooldridge, J. M. 2010. Econometric Analysis of Cross Section and Panel Data. Cambridge, MA: MIT press.

Yang, T., and H. E. Aldrich. 2012. "Out of Sight but Not Out of Mind: Why Failure to Account for Left Truncation Biases Research on Failure Rates." Journal of Business Venturing 27 (4): 477-492. doi:10.1016/j.jbusvent.2012.01.001. 


\section{Appendix A. Matching and unobserved bias}

The probability that company $i$ receives treatment, conditional on the explanatory variables $x_{i}$, is given by $P\left(x_{i}\right)=P\left(D=1 \mid x_{i}\right)=G\left(\beta x_{i}+\gamma u_{i}\right) . G($.$) is the logistic distribution, x_{i}$ are the observed variables, $u_{i}$ is the unobserved variable of observation $i$, and $\gamma$ is the effect of the unobserved variable on the probability of receiving treatment. If no unobserved bias exists, then $\gamma$ equals zero. If $\gamma$ is not zero, then an unobserved bias exists, and two companies that are similar in the observed variables $x_{i}$ will differ in the probability of receiving treatment. The odds ratio of two companies $i$ and $j$ that they will receive treatment is

$$
\frac{\frac{P\left(x_{i}\right)}{1-P\left(x_{i}\right)}}{\frac{P\left(x_{j}\right.}{1-P\left(x_{j}\right)}}=\frac{P\left(x_{i}\right)\left(1-P\left(x_{j}\right)\right.}{P\left(x_{j}\right)\left(1-P\left(x_{i}\right)\right)}=\frac{\exp \left(\beta x_{j}+\gamma u_{j}\right)}{\exp \left(\beta x_{i}+\gamma u_{i}\right)}=\exp \left[\gamma\left(u_{i}-u_{j}\right)\right] .
$$

The odds ratio equals one if no difference in unobserved bias exists; that is, when the difference $\left(u_{i}-u_{j}\right)$ is zero, or when the unobserved variables have no influence on the probability of receiving treatment; that is, when $\gamma$ equals zero. In all other cases, an unobserved bias exists and two companies that have the same observed covariates will still differ in the probability of receiving treatment. We assume that the unobserved variable is a dummy variable ${ }^{6} u_{i} \in[0,1]$ and Equation 1 implies the following "Rosenbaum-bounds" on the odds ratio that one of the two companies receives treatment:

$$
\frac{1}{e^{\gamma}} \leq \frac{P\left(x_{i}\right)\left(1-P\left(x_{j}\right)\right)}{P\left(x_{j}\right)\left(1-P\left(x_{i}\right)\right.} \leq e^{\gamma} .
$$

If $\Gamma=e^{\gamma}$ equals 1 , then there is no unobserved bias and both companies have the same probability of receiving treatment. Therefore, $\Gamma$ is a measure of the degree of allowed difference in the unobserved variables that influence the probability of treatment compared to the case with no unobserved bias. For example, if $\Gamma$ is equal to 1.5, then the two companies that are similar according to the observed variables could actually differ up to $50 \%$ in an unobserved way.

To evaluate the influence of the unobserved bias, we use the non-parametric Mantel-Haenszel test statistic (Mantel and Haenszel 1959) given by

$$
Q_{M H}=\frac{\left[\sum_{s=1}^{S}\left(Y_{1 s}-\frac{N_{15} Y_{s}}{N s}\right)\right]^{2}}{\sum_{s=1}^{S} \frac{N_{1 s} N_{0} Y_{s}\left(N_{s}-Y_{s}\right)}{N_{s}^{2}\left(N_{s}-1\right)}},
$$

where $N_{1 s}$ and $N_{0 s}$ are the numbers of treated and untreated individuals, respectively, in stratum $s$ with $N_{s}=N_{0 s}+N_{1 s} . Y_{1 s}$ is the number of successful participants, $Y_{0 s}$ is the number of successful non-participants, and $Y_{s}$ is the number of total successes in stratum $s$. This test statistic follows a $X^{2}$ distribution with one degree of freedom, and Rosenbaum (2002) shows that for a fixed value of $\Gamma>1$ and when $u_{i}$ is a $0 / 1$ dummy variable, $Q_{M H}$ is bounded by two known distributions. When $\Gamma$ increases, the bounds move apart, and hence reflect uncertainty about the test statistic. Furthermore, the following equation represents the two possible scenarios. $Q_{M H}^{+}$is the test statistic when the treatment effect is overestimated, and $Q_{M H}^{-}$is the test statistic when the treatment effect is underestimated:

$$
Q_{M H}^{+(-)}=\frac{\left[\sum_{s=1}^{S}\left(Y_{1 s}-\tilde{E}_{s}^{+(-)}\right)\right]^{2}}{\sum_{s=1}^{S} \operatorname{Var}\left(\tilde{E}_{s}^{+(-)}\right)},
$$

where according to Aakvik (2001), $\tilde{E}_{s}$ and $\operatorname{Var}\left(\tilde{E}_{s}\right)$ are the large sample approximations to the expectation and variance, respectively, of the number of companies receiving treatment, $Y_{1 s}$, when $u$ is binary, and for a given $\Gamma$. 


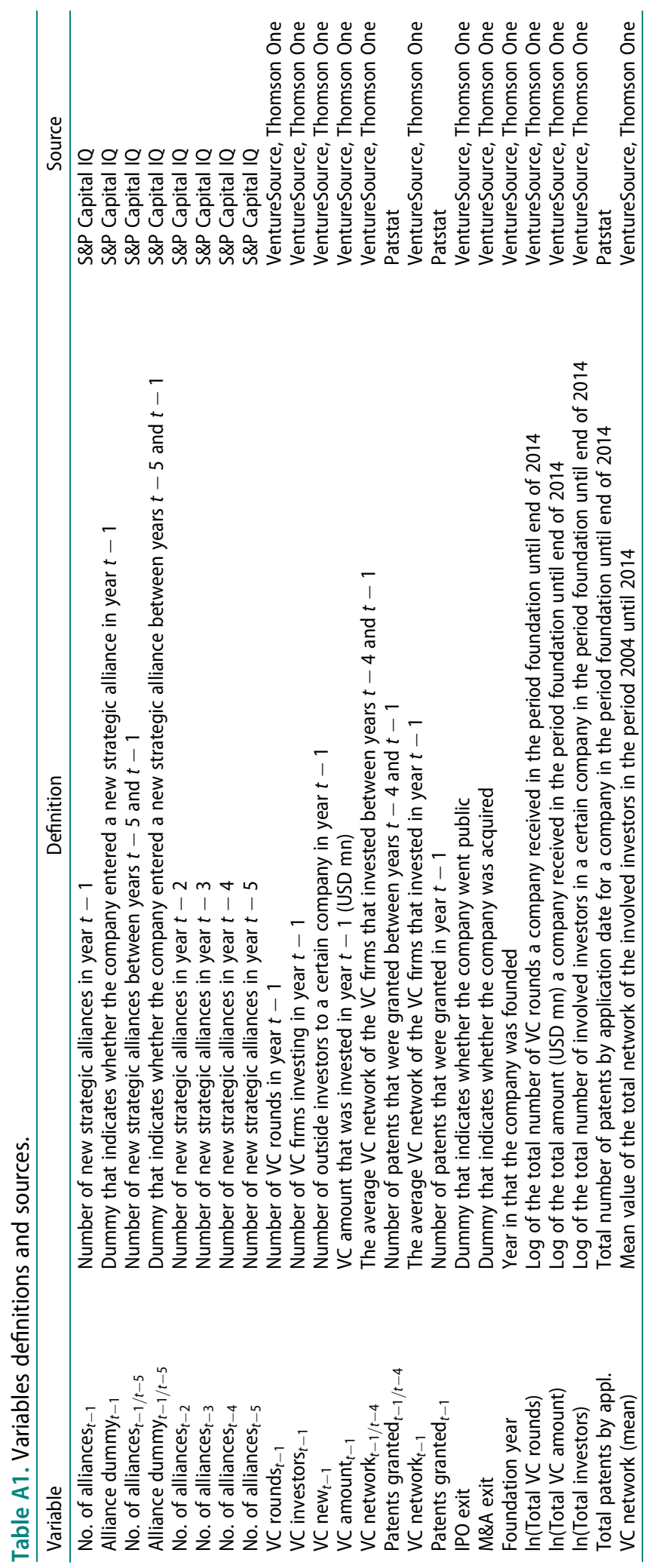

